Journal of Engineering Sciences, Assiut University, Vol. 37, No. 3, pp. 813-828, May 2009.

\title{
THE ROLE OF FINE RESTORATION TECHNIQUES IN MAINTAINING HERITAGE BUILDINGS' ORNAMENTS (THE ORNAMENTS OF ALAMRYA SCHOOL IN YEMEN, AS AN APPLIED EXAMPLE)
}

\section{Shawkat El-Kadi Mohammed. A. Mosa}

Associate Professor

Professor of Architecture,

Sahar M. Anas Al-Eryani

Dept. of Architecture, Assiut University

(Received March 4, 2009 Accepted April 7, 2009)

The technological development in restoration is one of the most important modern pillars that constitute the conservation process for any element of the heritage building elements. As ornaments are very important elements in many heritage buildings; any development in the field of fine restoration techniques, will have a marked effect on ornaments' restoration project in the future. The study aims mainly to identify the role of fine restoration techniques in maintaining heritage buildings ornaments, so as to exhibit the solutions and facilities, these techniques offer, so as to be added to the integrated conservation processes. To achieve the aim of the study, the most important techniques- used in restoring ornaments- are analyzed. While in the second part, Alamiria school in Yemen- one of the conservation processes of heritage buildingsis introduced. Consequently, the ornaments' restoration processes is evaluated from the prospect of current fine restoration techniques.
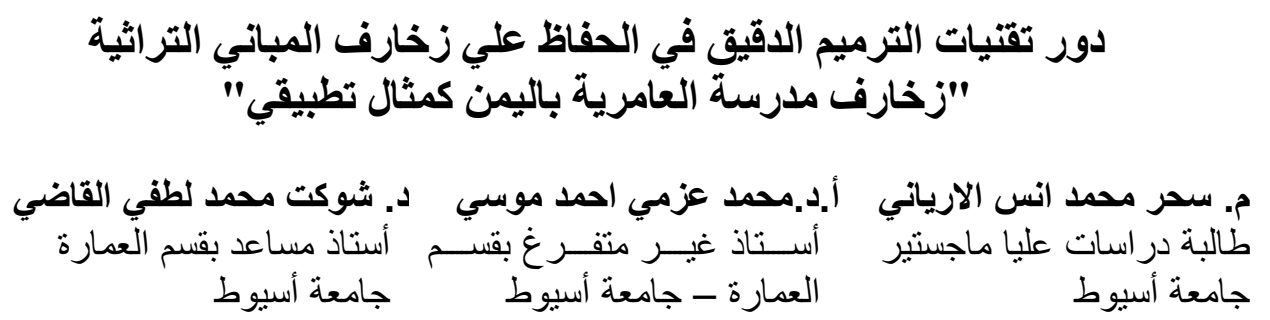

يعتبر التطور التقني في مجال الترميم من أهم الركائز الحديثة المشكلة لعملية الحفاظ لأي عنصر من عناصر

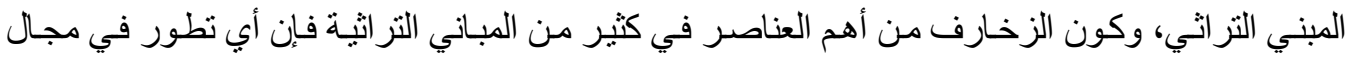

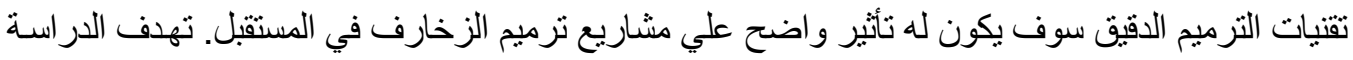

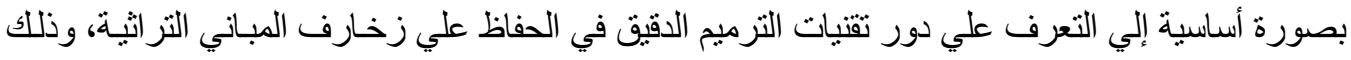
من اجل إبراز مـا تقدمهـ هذه التقنيات مـن تسـيلات وحلول يمكن إضـافتها إلـي عمليـات الحفـاظ المتكاملـة،

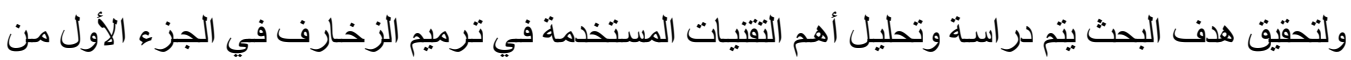
الدراسة، بينما يتم في الجزء الثاني من البحث التعرف علي احد أعمـال الحفاظ علي الزخـارف في المباني 
التراثية و هي مدرسة العامرية باليمن، ومن ثم تقيبم أعمال ترميم الزخارف من منظور تقنيات الترميم الدقيق

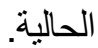

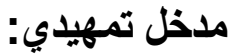

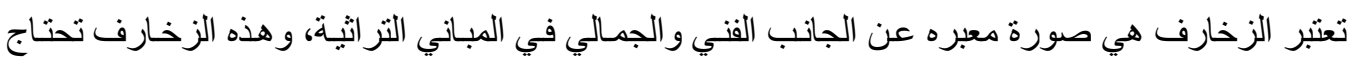

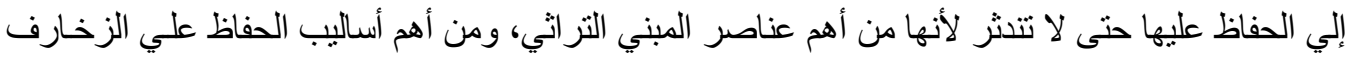

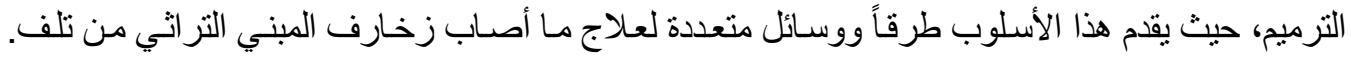

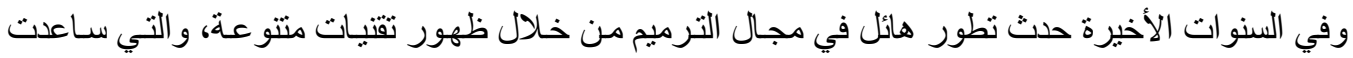

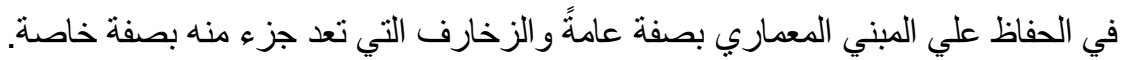

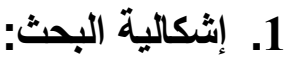

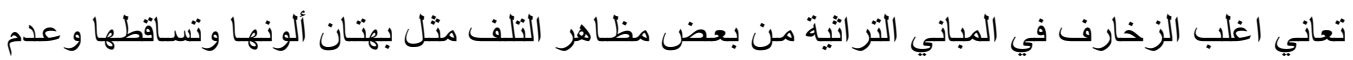

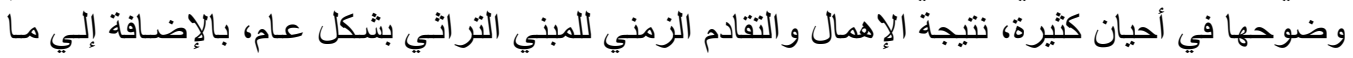

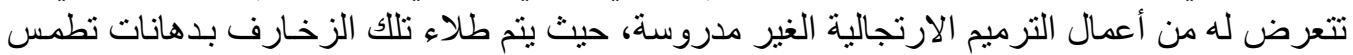

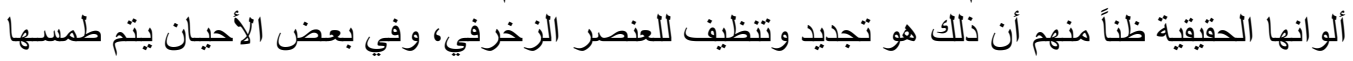

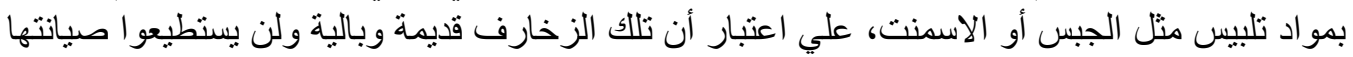

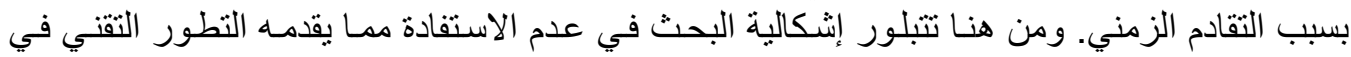

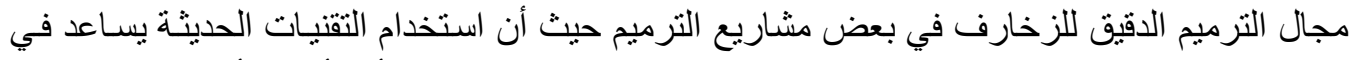

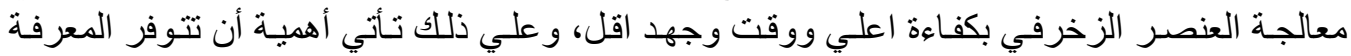

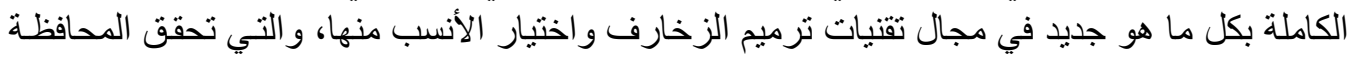
عليها دون مس في قيمنها الفنية و الجمالية و التاريخية. 2.

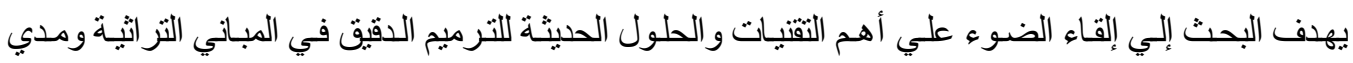

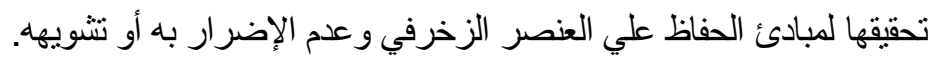

\section{3. مكونات البحث:}

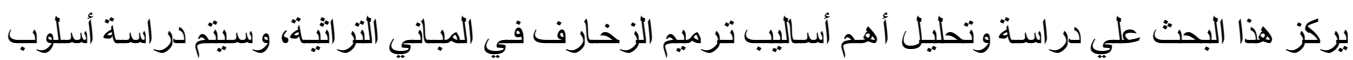

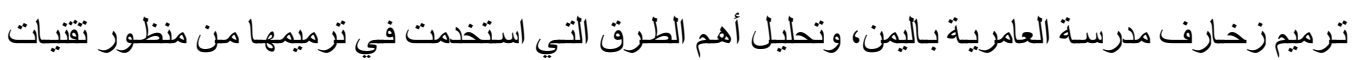

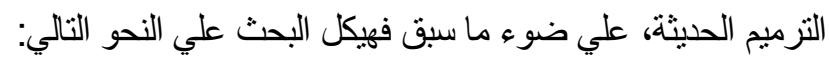

1-3. الترميم الدقيق كأحد عناصر منظومة الترميم المتكامل.

$$
\text { تقنيات الترميم الدقيق للزخارف. }
$$

زخارف مدرسة العامرية باليمن كمثال من حيث المعالجات التي تمت أثناء عملية الترميح.

تقييم هذه المعالجات من منظور تقنيات الترميم المتاحة و الحديثة.

الترميم الاقيق كأحد عناصر منظومة الترميم:

.1-3

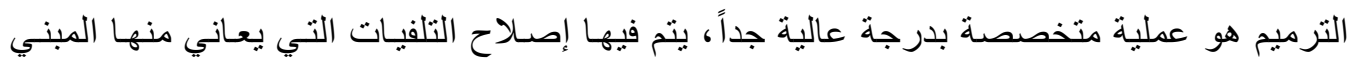

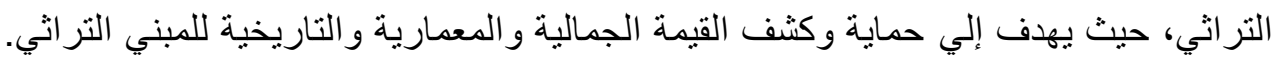


ويمكن أن يطلق الترميم الدقيق علي جميع أعمال الترميم التي تجري لصيانة المبني التراثي وعلي وجه الخصوص العناصر الزخرفية الموجودة في حو ائط و أسقف المبني التيني.

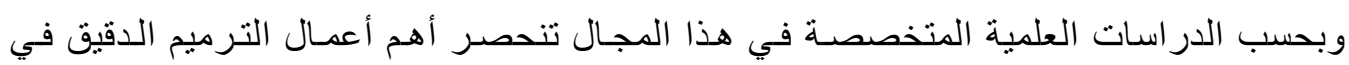
الأتي:[نشاهين، 1994

عمليات تنظيف وترميم النقوش الجدارية والزخارف و الحليات وتتبيت ألوانها. عمليات ترميم جميع العناصر المرتبطة بالنحت و التصوير و النقش.

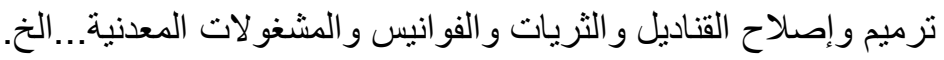

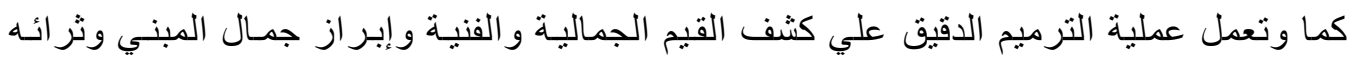

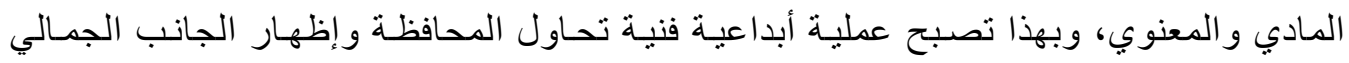

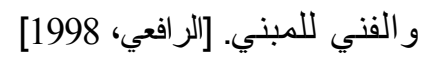

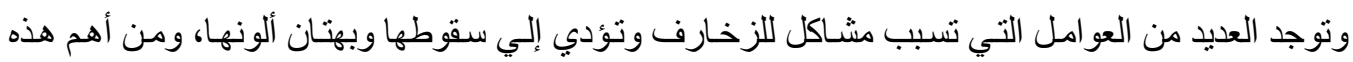

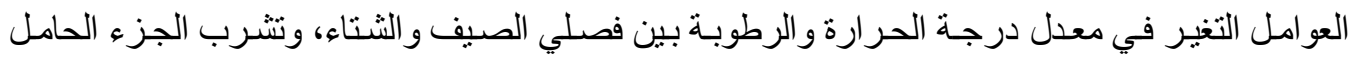

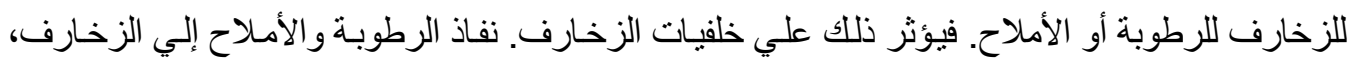
يؤدي إلي ظهور عدة عيوب يلزم معالجتها منها:

$$
\text { شروخ سطحية. }
$$

شروخ عميقة وتصدعات في الطبقة الخلفية للزخارف وطبقة الألوان.

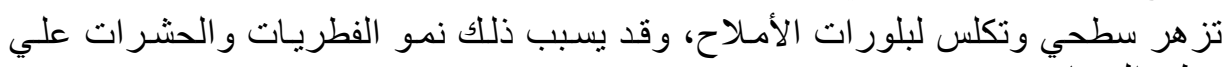
سطح الزخارف. بهتان درجات ألوان الزخارف الزفار نتيجة تحلل الوسيط المستخدم.

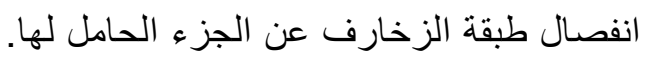

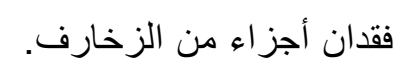
طمس معالم الزخارف بسبب تر اكم طبقات السناج و المو اد الدهنيه و الأوساخ الناتجة عن الحشرات.

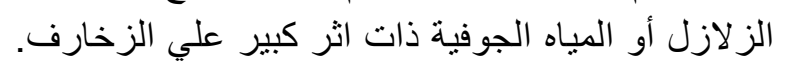

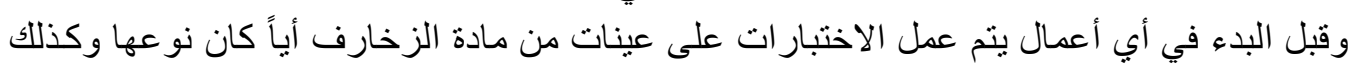

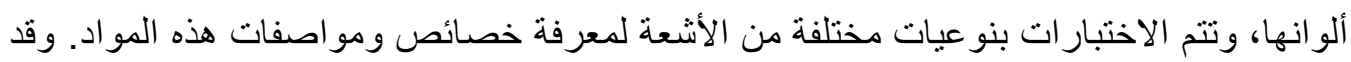

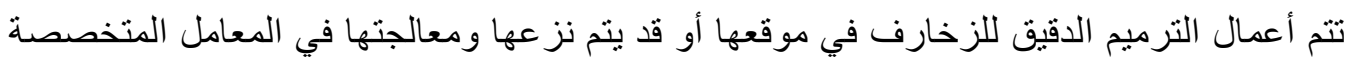

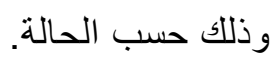

\section{2-3 تقتيات الترميم الاقيق للزخارف:}

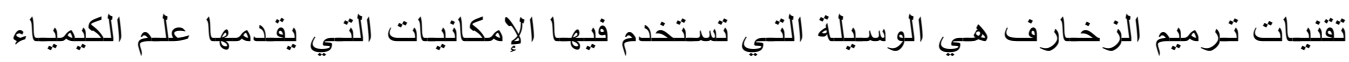

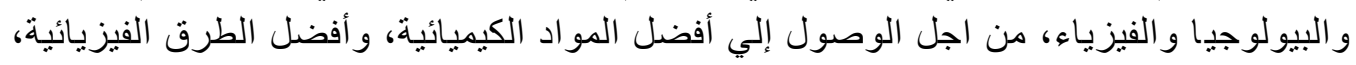

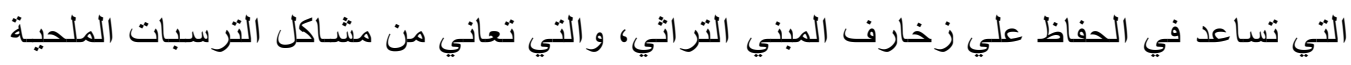

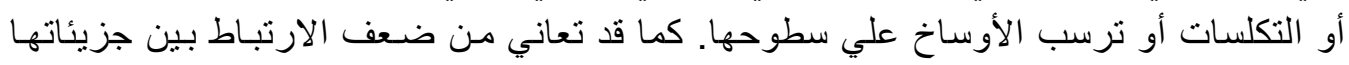

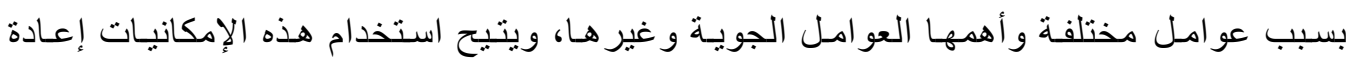

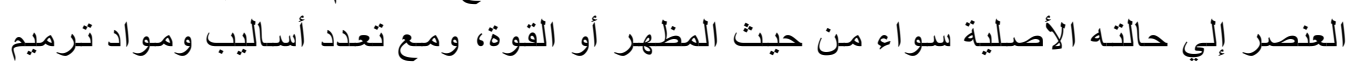


الزخارف يحاول المتخصصون اختيار الأنسب والذي يسبب اقل سلبيات علي العنصر الزخرفي

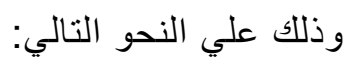

\section{1-2-3. تقنيات عملية التنظيف للأوساخ والأتربة (Cleaning):}

إن عملية التنظيف للزخارف يجب أن تنت بحذر كبير لأن تلفها سريع. وتتحصر أهم تقنيات التنظيف فيما

\section{1-1-2-3. تقنية التظيف الميكاتيكي بطريقة النحت أو الكثط (Chiseling or Scraping):}

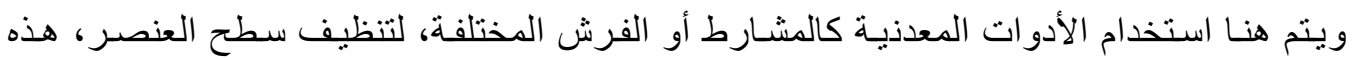
الطريقة قد تأخذ فترة زمنية طويلة.

\section{2-1-2-3. تقنية التظيف الكيميائي (Chemical Cleaning):}

في هذا الأسلوب يتم استخدام مواد ومركبات كيميائية تساعد في عملية التنظيف وهي كما يلي:

$$
\text { أ- المحاليل الكيميائية: [مهران، 2007) }
$$

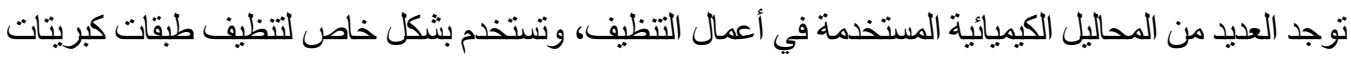

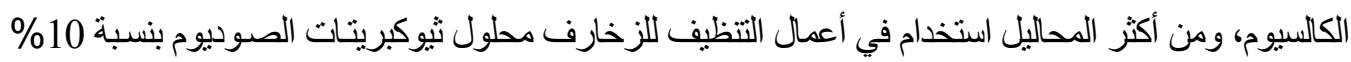

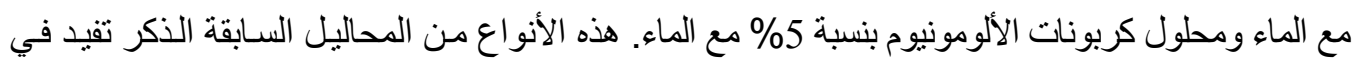

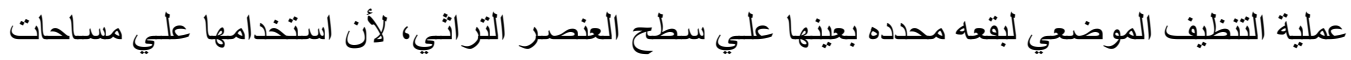

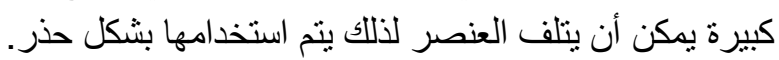

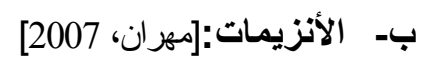

هي من مو اد التنظيف الحديثة، تعمل عند استخدامها علي زيادة التفاعلات الكيميائية دون أي تغيير في التوازن

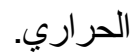

\section{ج- الهلاميات القلوية(Basic Jellies):توركا، 2003]}

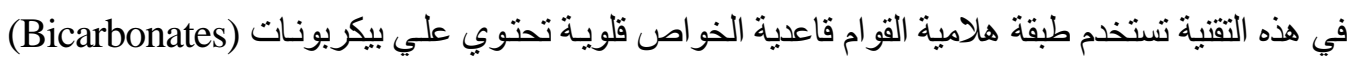

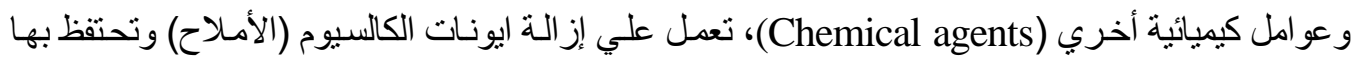

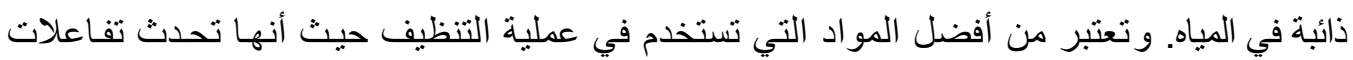

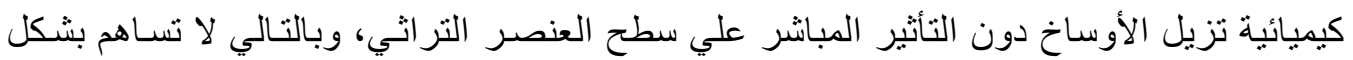
كبير في تدمير مادة العنصر.

دـ الأحماض والقلويات (Acids and Alkines):

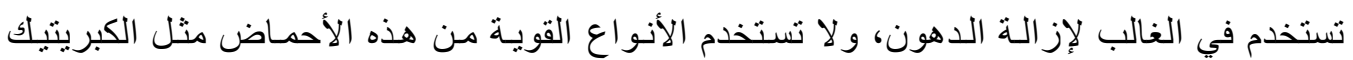

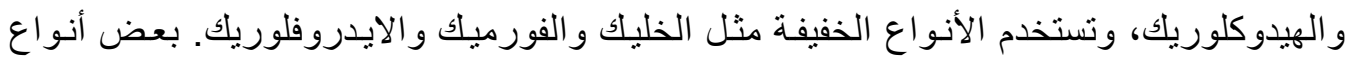

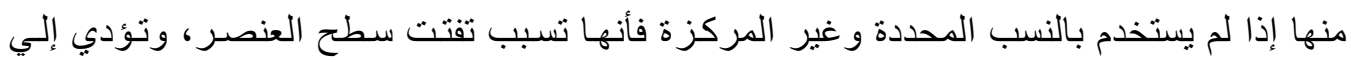

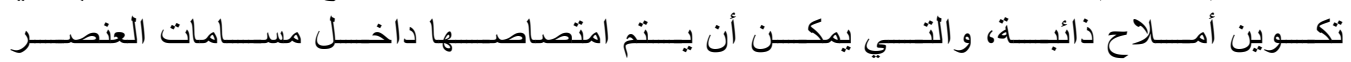

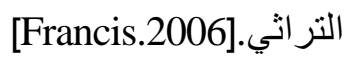

هـ المنظفات الصناعية (Surfactants Cleaning ): 
هذه المنظفات ينم إطلاقها تجارياً في السوق علي شكل عبو ات تحتوي في تركييها علي مادة كربوكس

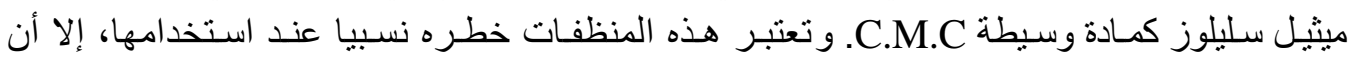

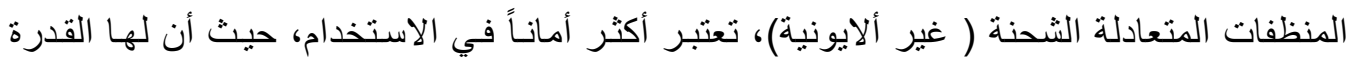
علي التنظيف دون إطلاق أيونات خطرة قد تتلف العنصر التراثي في المستقبل.[محد، 1996]

\section{و- المذيبات العضوية (Organic Solvents) :}

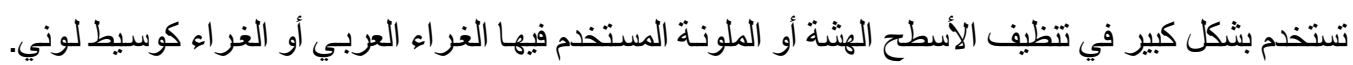

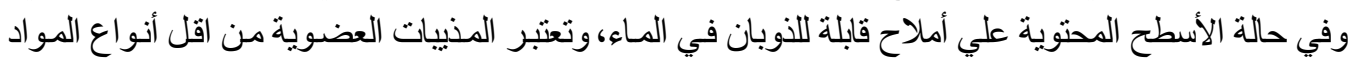

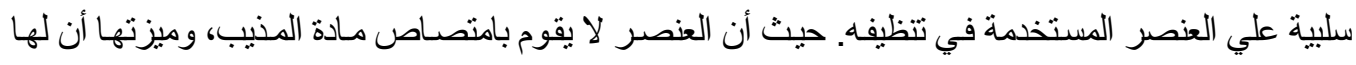
القدرة علي إز الة الدهون والأوساخ العضوية التي يصعب أز التها بالطرق الأخرى.[محمد، 1996]

\section{3-1-2-3. تقتية التظظف الفيزيائي بأثنعة الليزر(Leaser Cleaning):}

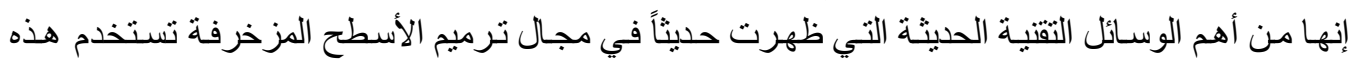

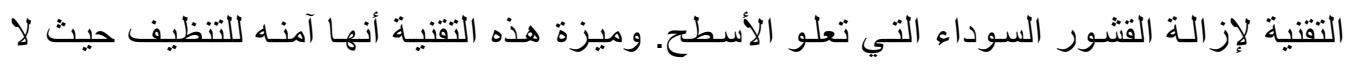

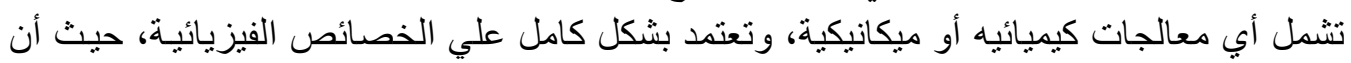

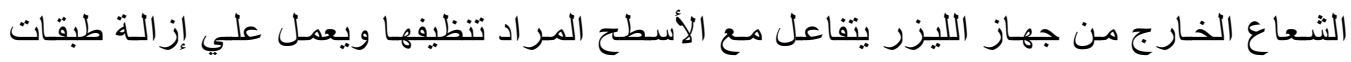

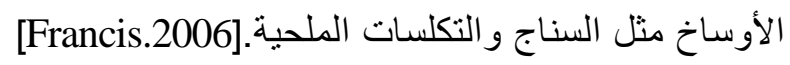

\section{4-1-2-3}

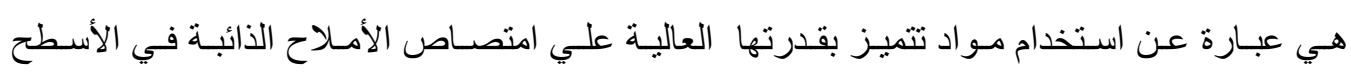

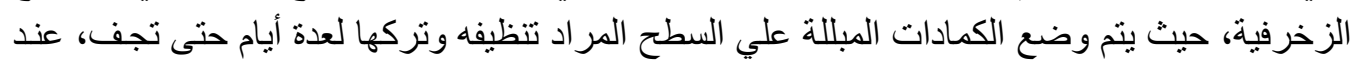

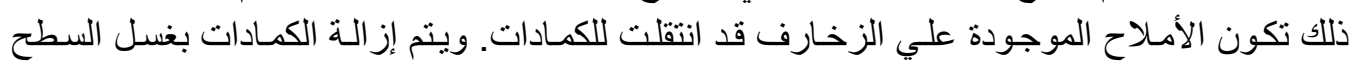

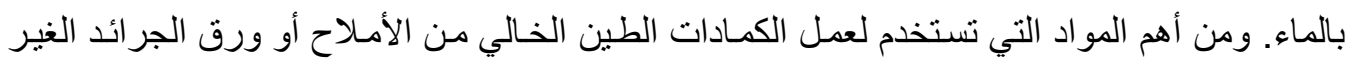

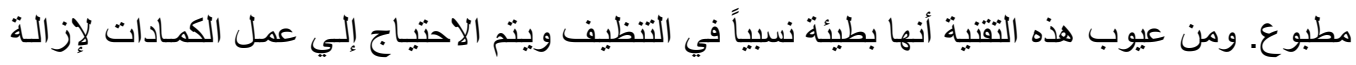

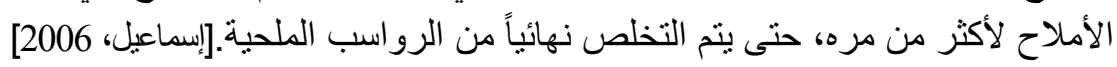
2-2-3 . تقنية معالجة الثقوق واستكمال المفقود من الزخارف:[عنية، 2005]

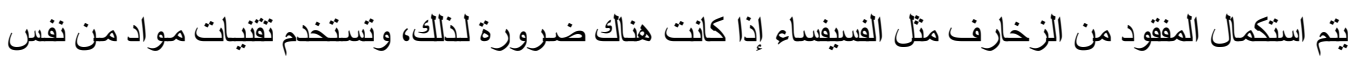

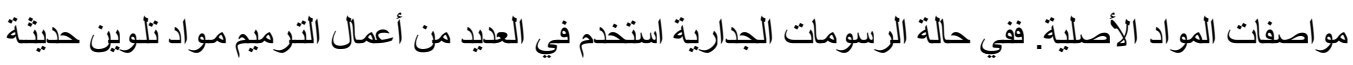

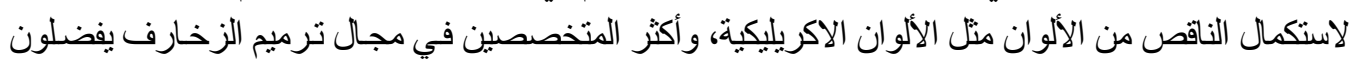

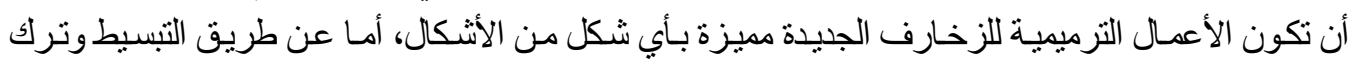
التفاصيل وإما بتأريخ الأعمال الجديدة أو باستخدام الفن و التقنية الحديثة.

\section{تقنيات التقوية (Consolidation): توركا، 2003]}

$.3-2-3$

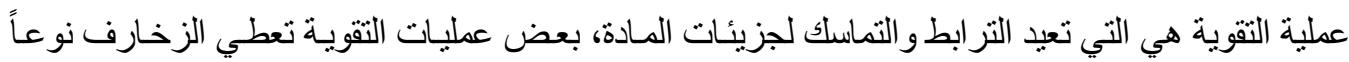

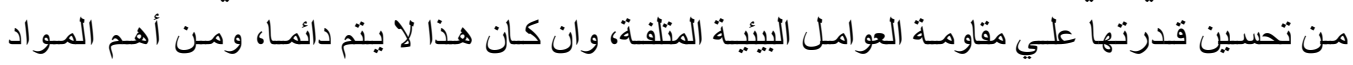
المستخدمة في عمليات التقوية التالي: 
أ- المقويـات العضوية الطبيعية (Natural organic Materials): مثل الزيوت وزلال

البيض وشمع النحل و الغز اء و الأصماغ.[مهران، 2007)

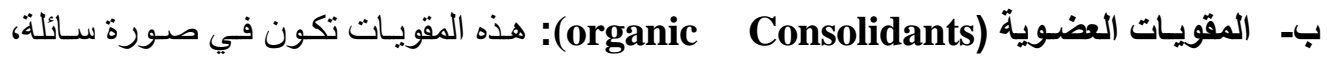

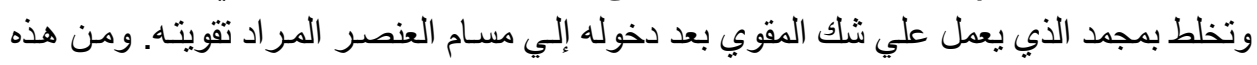

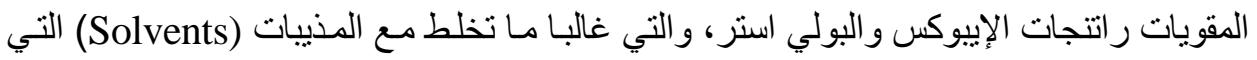

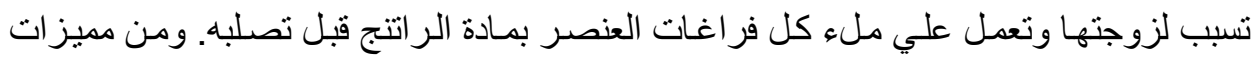

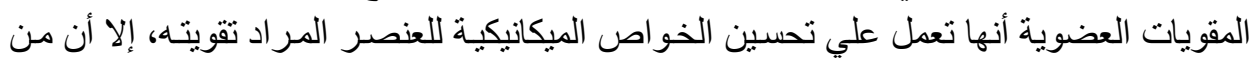

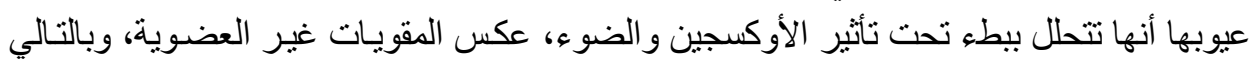

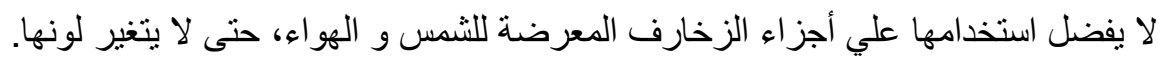

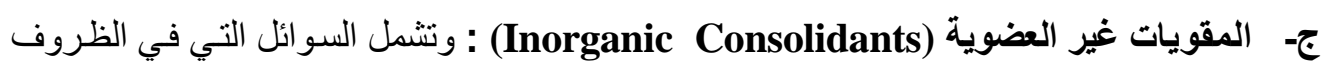

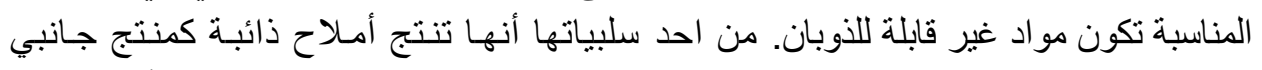

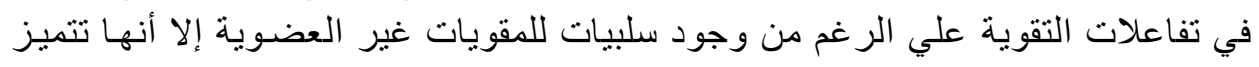

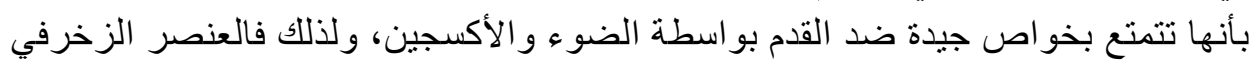

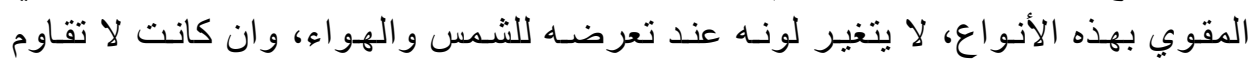
التلف الناتج عن الصدمات الميكانيكية.

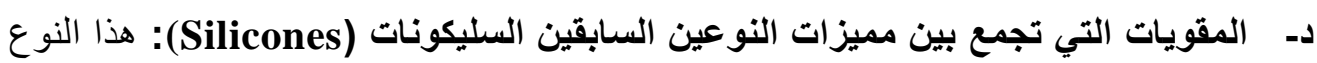

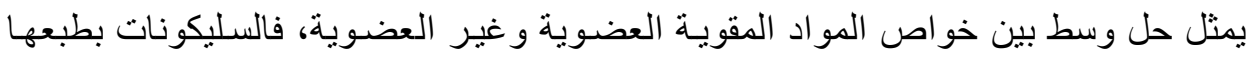

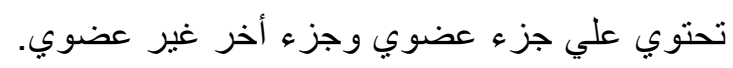

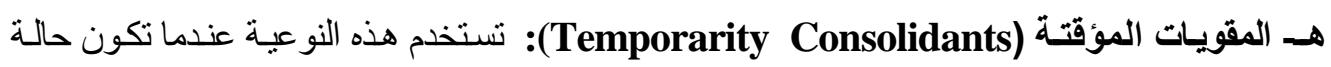

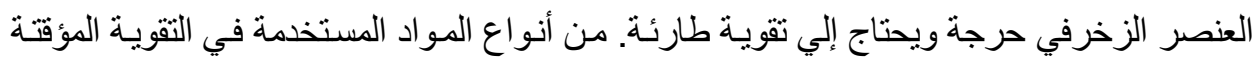

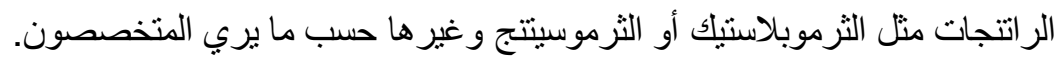

\section{4-2-3. تقنيات عمليات الحماية للأسطح (Protection):}

بعد عملية التنظيف و التقوية للعنصر الزخرفي، نأتي خطوه مهمة وهي حماية السطح الخارجي لمـادة العنصر

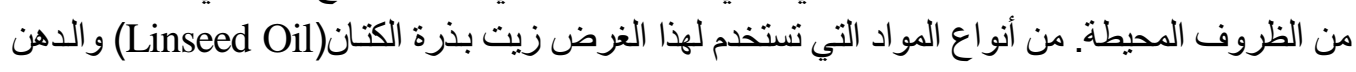

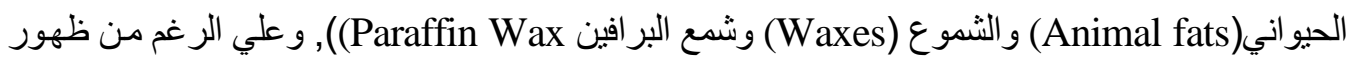

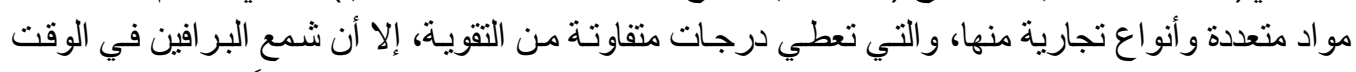

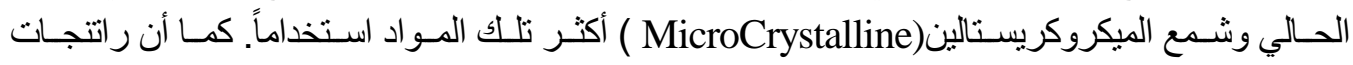

الأكريلك و السليكونات تستخدم أيضاً كمادة حماية سطحية. [نوركا، 2003]

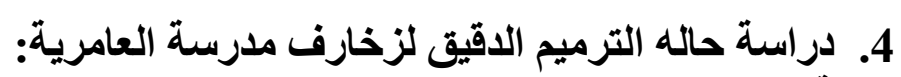

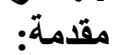

توجد المدرسة العامرية في مدينة رداع الو اقعة ضمن المناطق الوسطي في اليمن وقد بناهـا تحديداً السلطان

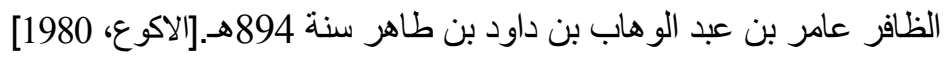


شكل (1): مدرسة العامرية باليمن http://archnet.org/library/in ages/oneimage.jsp?location _id=6287\&image_id.

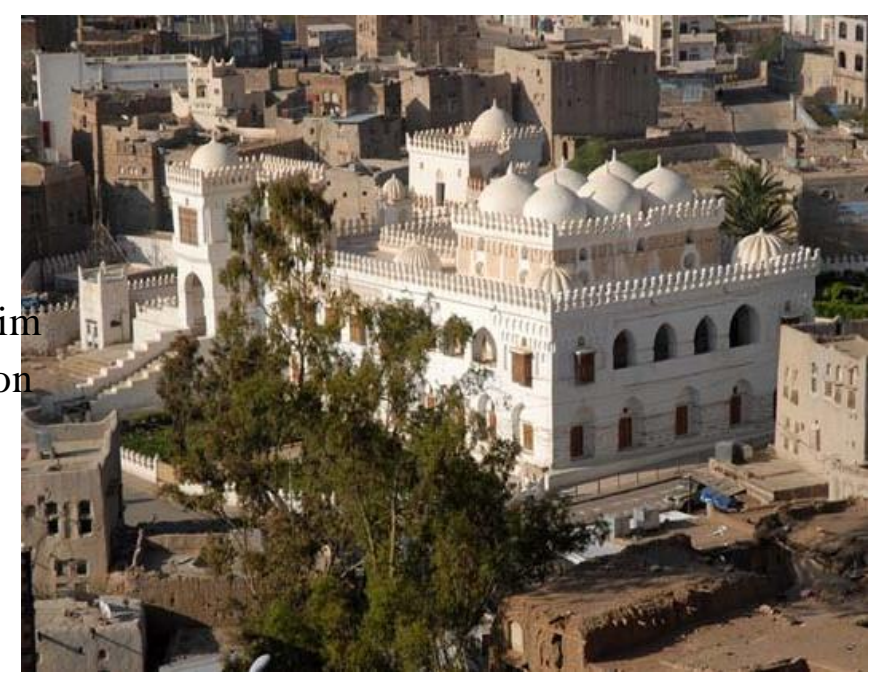

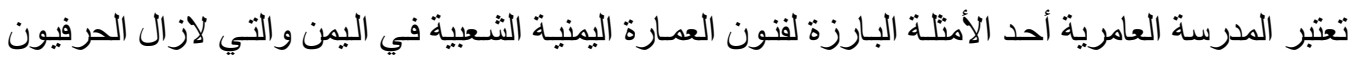

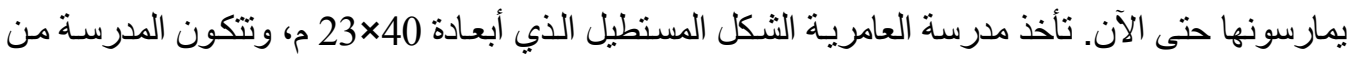

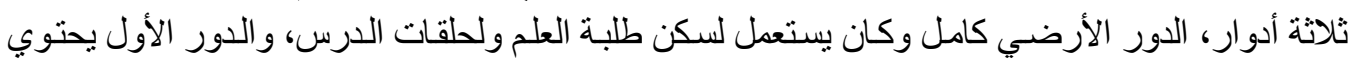

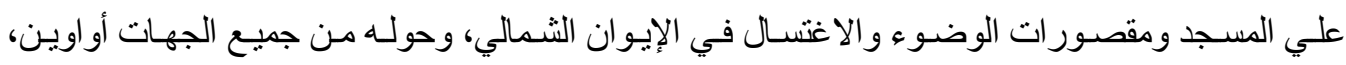

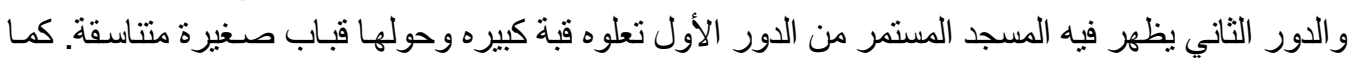

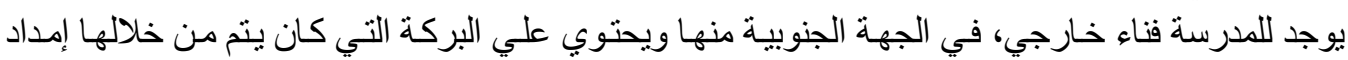
المدرسة بالمياه بالإضافة إلي بعض في الحمامات و المو اضئ. 1-4. وصف زخارف المدرسة العامرية:

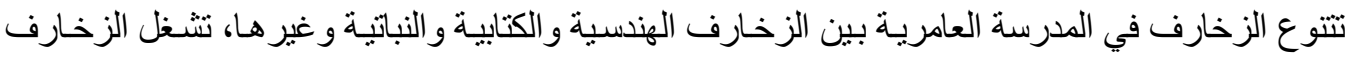

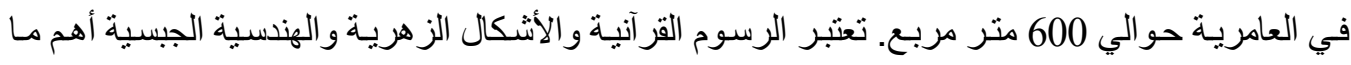

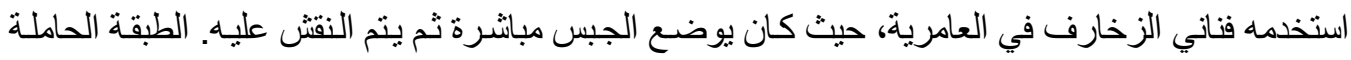

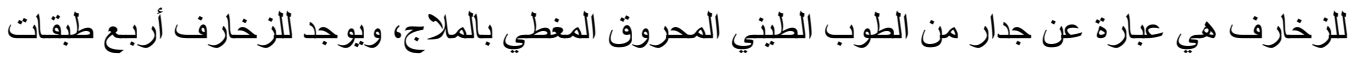

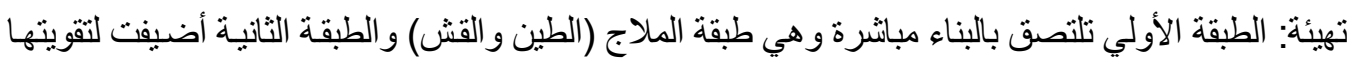

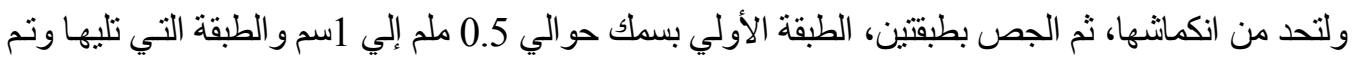
الزخرفة عليها بسماكة لا تزيد عن 2 مله. 

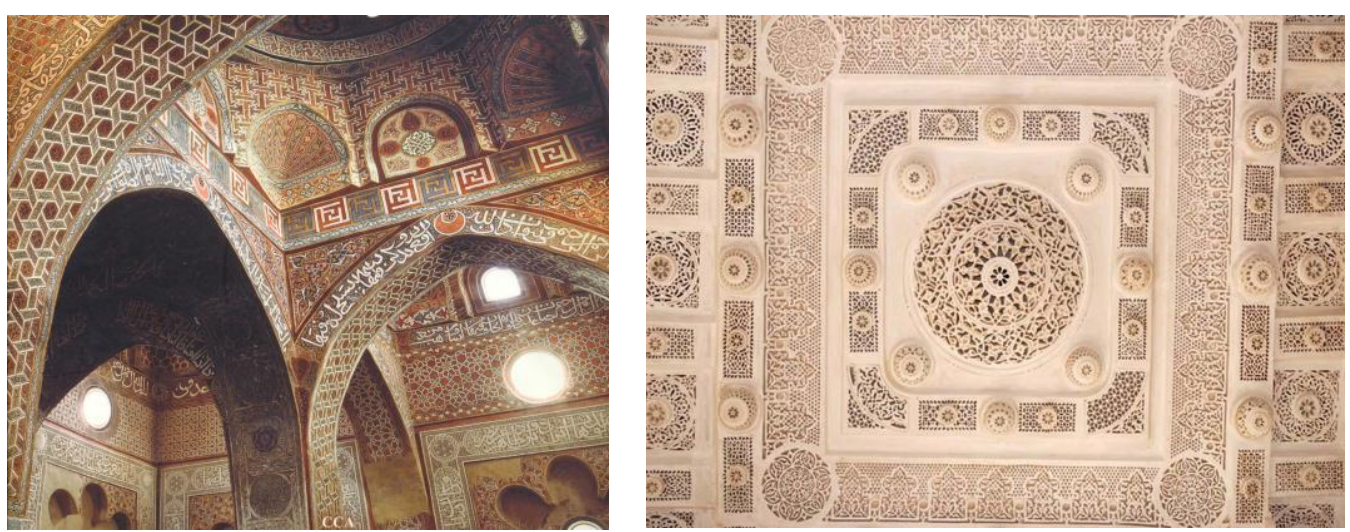

شكل (2): صور لبعض زخارف المدرسة

http://archnet.org/library/parties/one-party.jsp?party_id=427

2-4. مظاهر التلف في الزخارف:

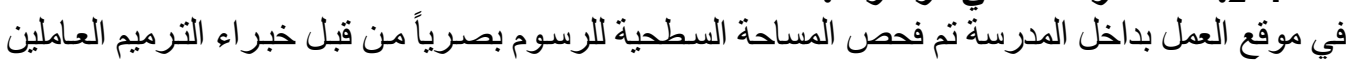

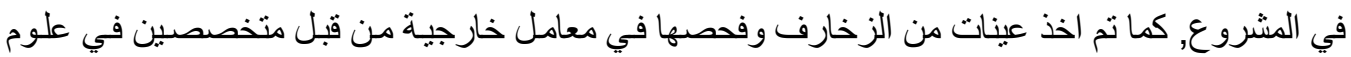

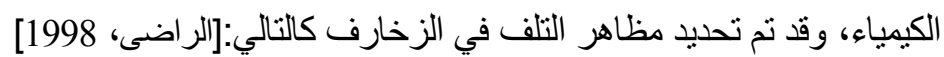

$$
\begin{aligned}
& \text { • نر اكم الأكاسيد الكربونية والأملاح }
\end{aligned}
$$

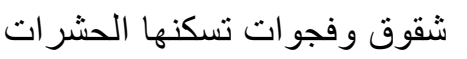

$$
\begin{aligned}
& \text { الرطوبة }
\end{aligned}
$$

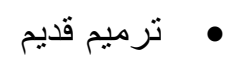$$
\text { • • • • • تر اكم الغبار و القشر الملحية }
$$$$
\text { • • • • • • • }
$$

و اغلب مظاهر التلف كان سبيها الأمطار التي كانت تتسرب إلي الداخل والهزات الأرضية التي حدثت في المنطقة في فترات مختلفة.
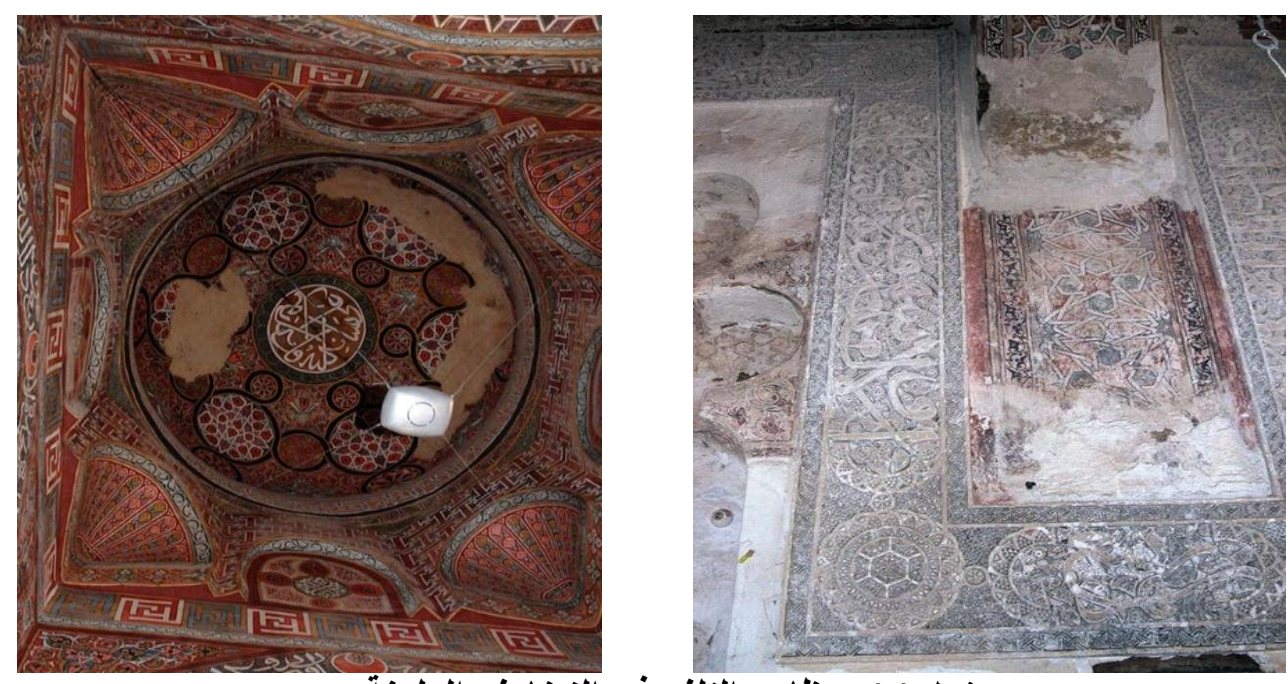

شكل (3): مظاهر التلف في الزخارف الملونـة

http://archnet.org/library/parties/one-party.jsp?party_id=427 
3-4 . تقتيات الترميم الدقيق لزخارف المدرسة العامرية:

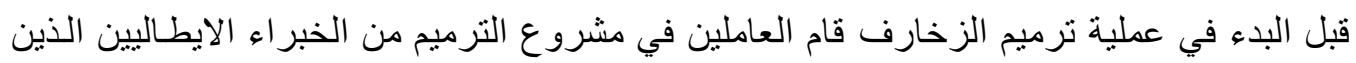

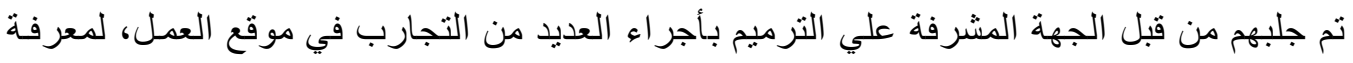

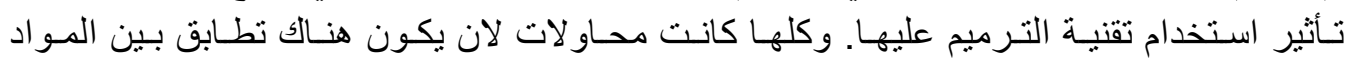

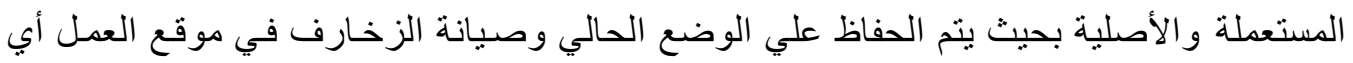

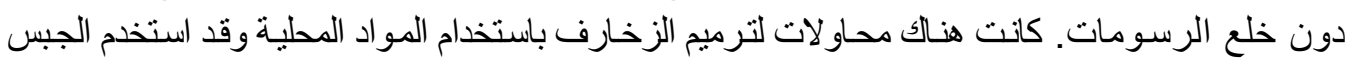

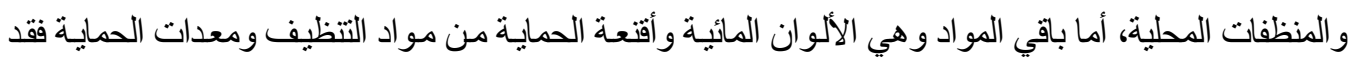
تم جلبها من ايطاليا. و هنا سوف نتعرض لخطوات ترميم الزخارف و اهم التقنيات المستخدمة في ذلك كما يلي:

\section{1-3-4 . تقنية تنظيف الأسطح المزخرفة:[الراضى، 1998]}

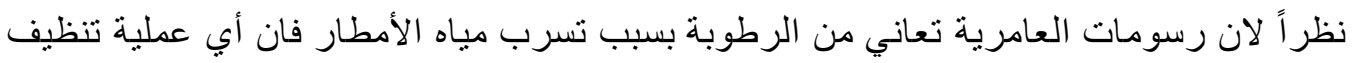

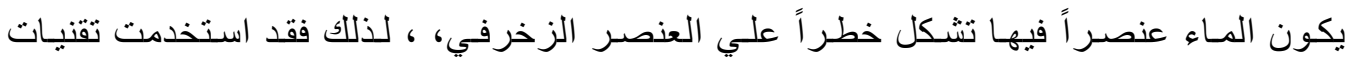

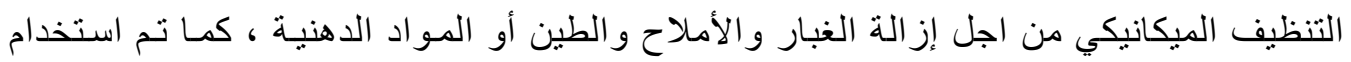

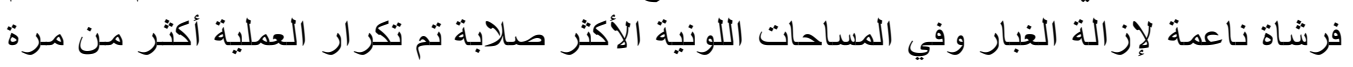

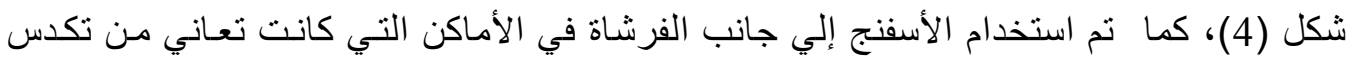

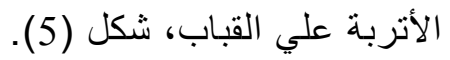

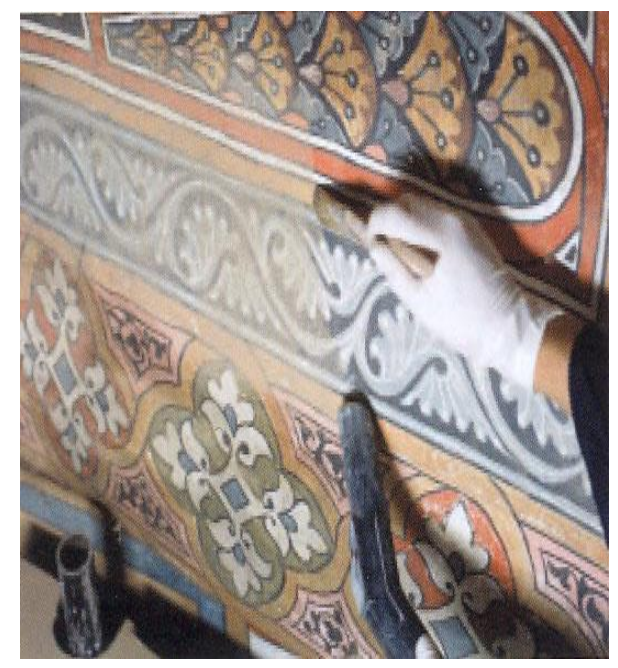

تنظيف الزخارف بواسطة الفرشاة

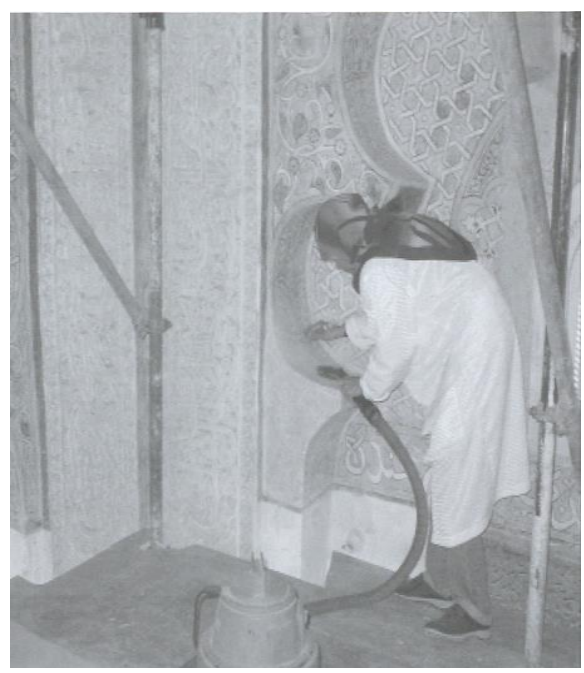

تنظيف الزخارف بواسطة الشفط الميكانيكي شكل (4): أعمال التظظف للزخارف بواسطة الثفط الميكانيكي والفرشاة. [التقارير، 2004] 


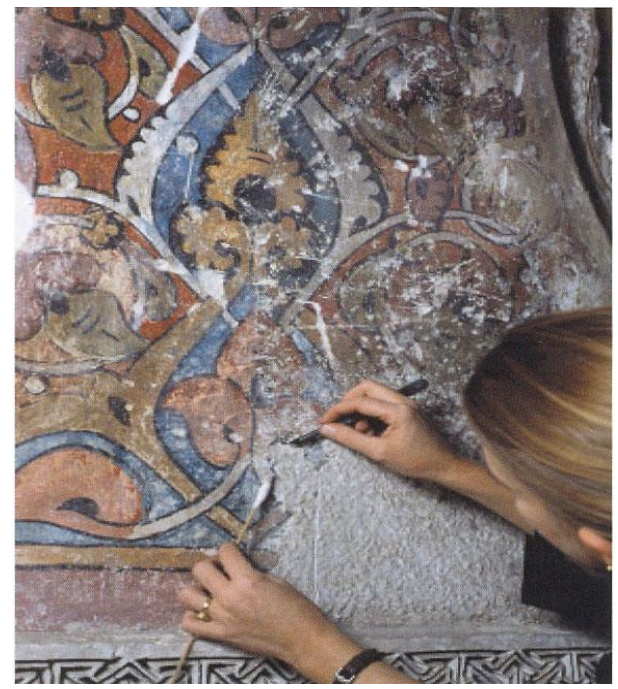

التنظيف بواسطة المكاشط

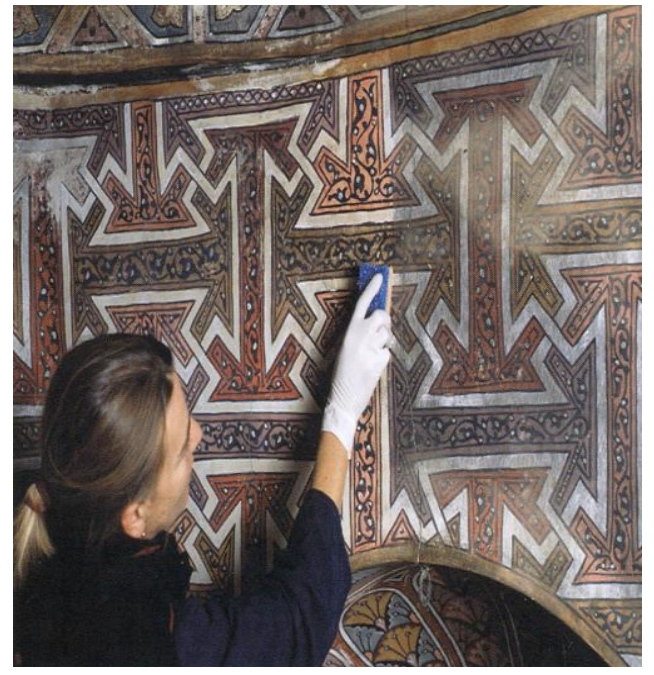

التظيف باستخدام الأسفنج

شكل (5): أعمال التنظيف للزخارف باستخدام الأسفنج و المكاشط. [النقارير، 2004]

المساحات الزخرفية التي كانت تعاني من اسوداد لونها بسبب الدخان الأسود الناتج عن فو انبس الإضاءة

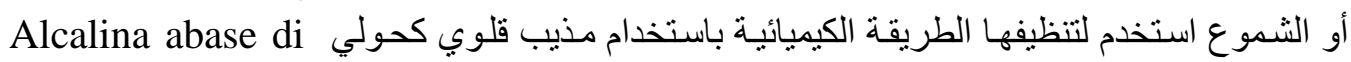
(Ammoniaca) و والأمونيكا (Acetone) و والميتون (alcool etilico) لأكثر من مرة واحدة بواسطة منديل ورقي، شكل (6)، بعض الأماكن التي لايز ال بها سو اد تم استخدام

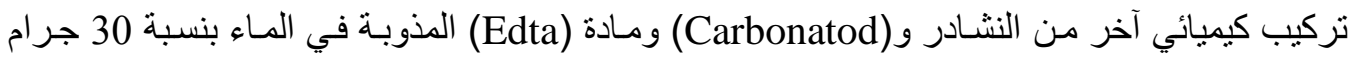

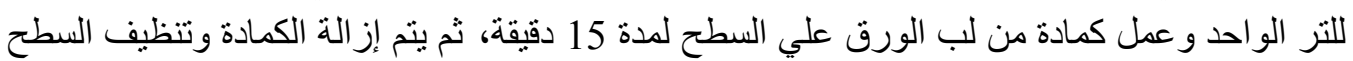

شكل (6): التنظيف الكيميائي للاخان

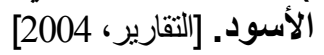

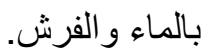

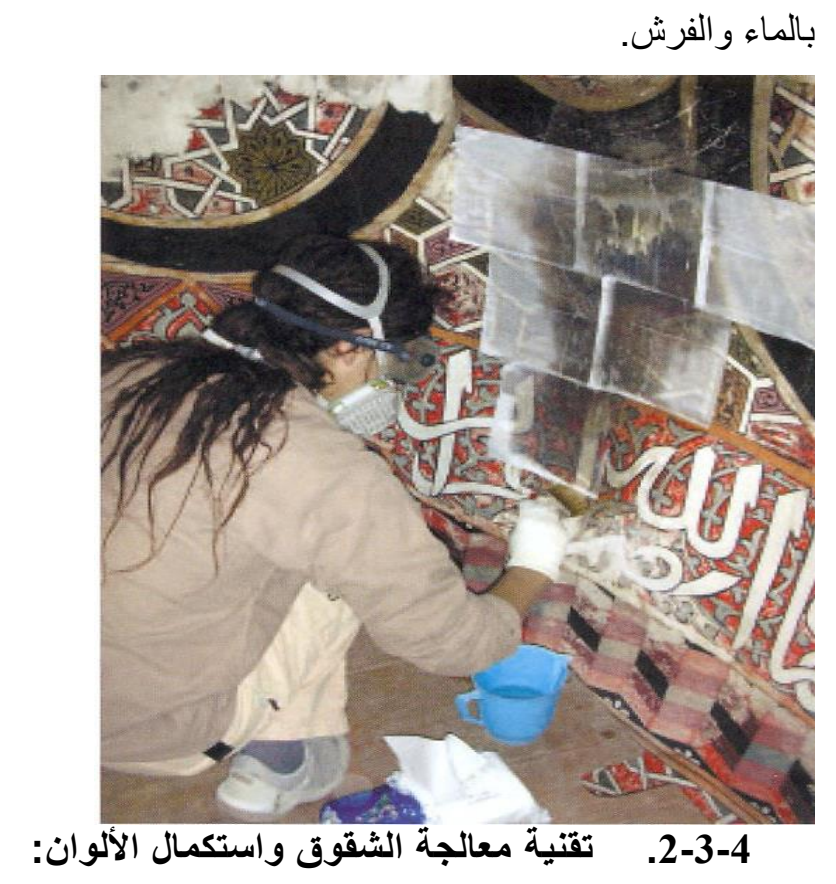




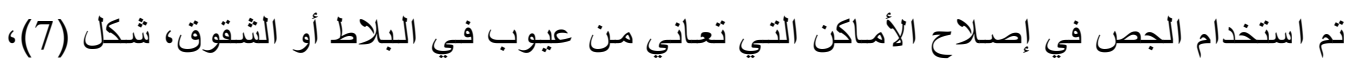

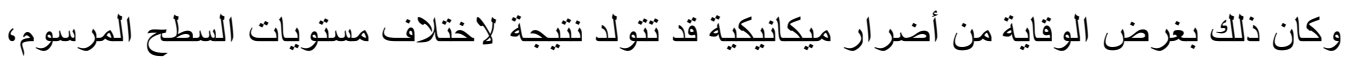

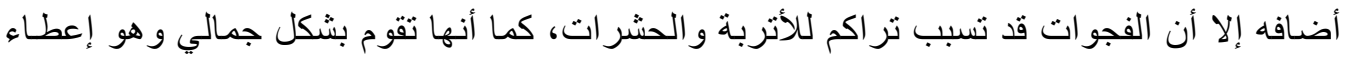

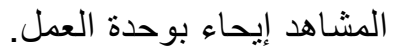

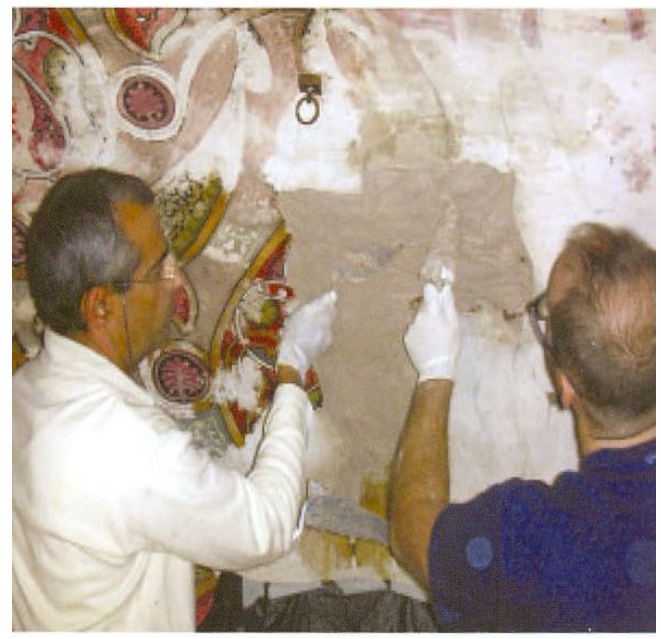

تزميم آماكن الزخارف المفقودة شكل (7): تقنيات ترميم الثقوق في الزخارف [التقارير، 2004]

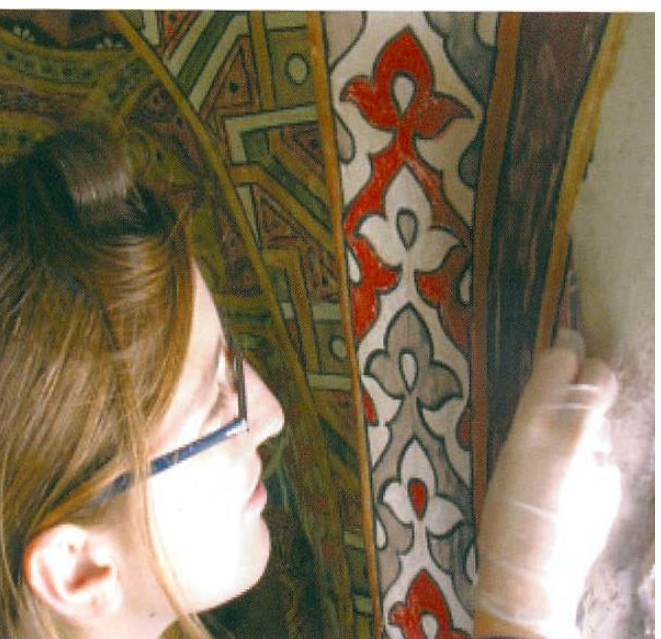
ترميم الثقوق باستخدام الملاط الكلسي

إن تقنيـة استكمال مـا فقد من القتـرة اللونيـة لم تستخدم إلا في الأمـاكن التي تعرضت الإضـرار

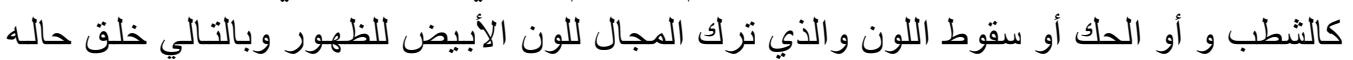
متغيره لقر اءة اللوحة الفنية، شكل (7) ألو الفون

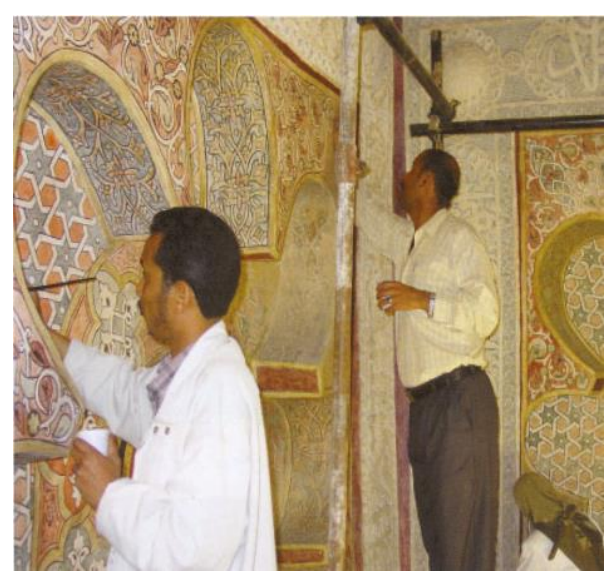

استكمال الألوان في قاعة الصلاة

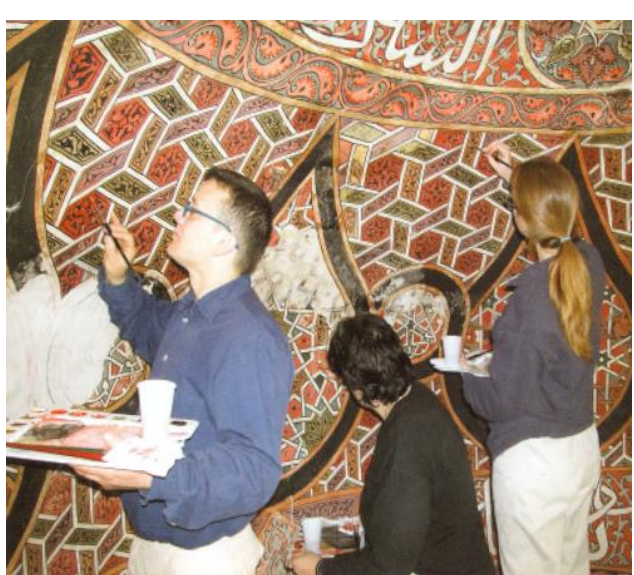

أعمال استكمال الألوان الناقصة في القبة الأولي

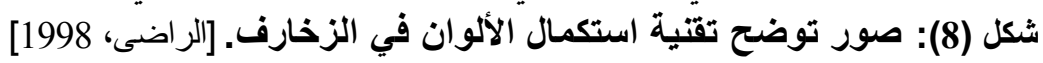

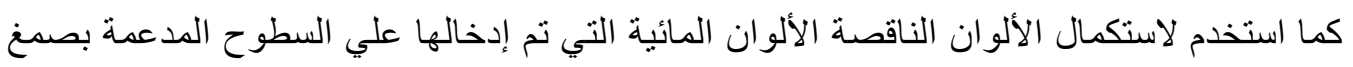

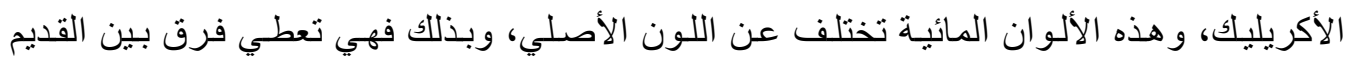

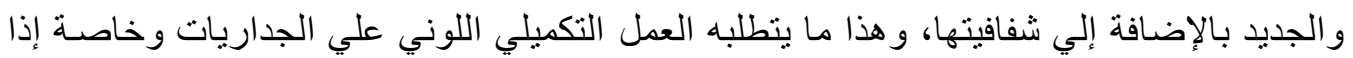


نم استخدامها علي سطح الطلاء الأصلي. هذا التذخل لم يعمم في جميع الأمساكن و إنما كان اغلبها في النقوش الدينية (8).[الراضى، 1998]

\section{3-3-4. تقنتيات التقوية:}

تم تقسيم أعمال التقوية إلي جزئيين تقوية مؤقتة وتقوية دائمة وسيتم استعر اضها كما يلي:

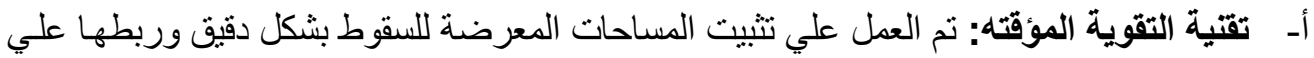

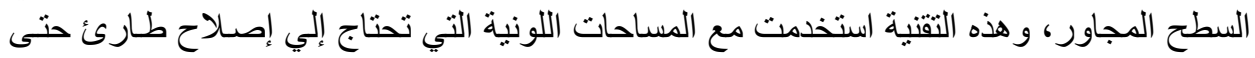
يتم البدء في ترميمها. وقد تم ذللك بالخطوات التالية: [الراضى، 1998]

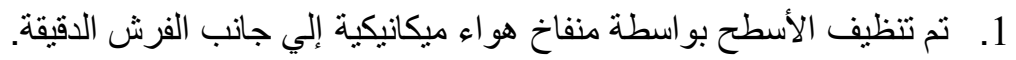

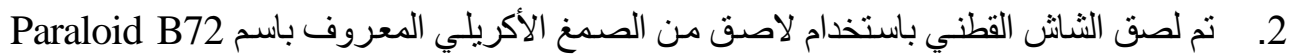
ومذوب بنسبة 15 \% في أسيتون.

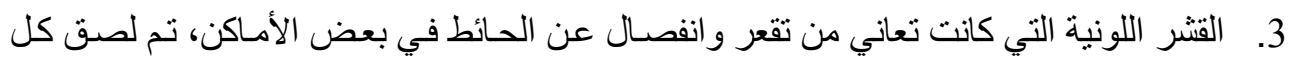

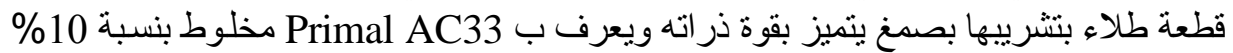
ماء.

بـ تقتية التقوية الدائمة: ظاهرة الانفصال بين طبقات الطلاء نفسها أو بين طبقة الطلاء و الطبقة الحاملة

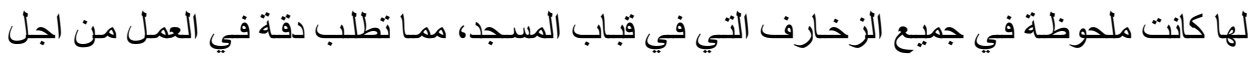

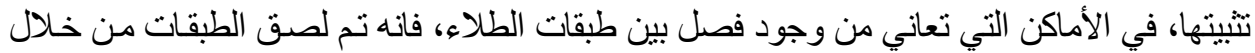

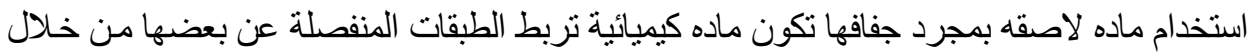

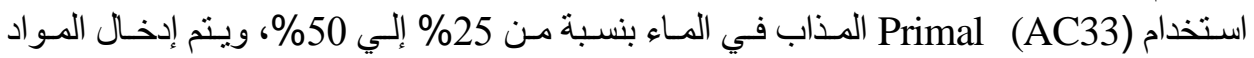

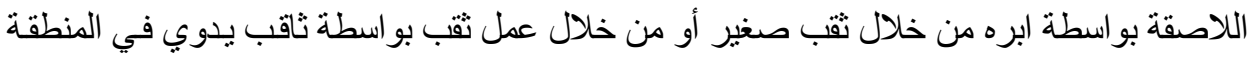

المر اد علاجها شكل (9).
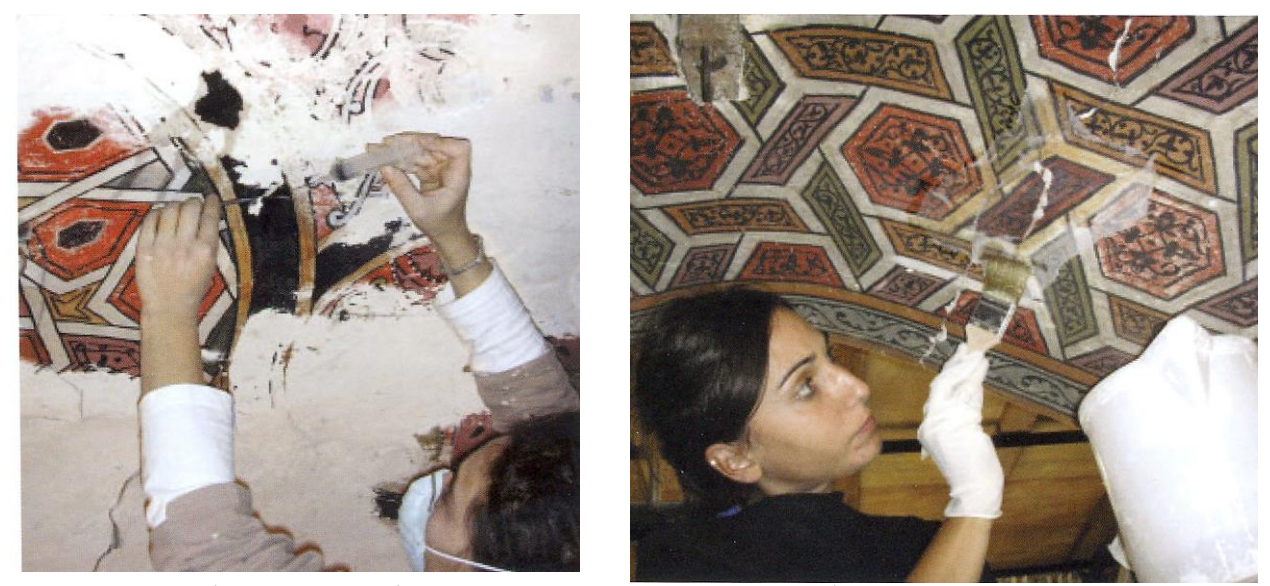

شكل (9): تثبيت القطع اللونية التي انفصلت عن الطلاء بواسطة مواد كيميائية واصماغ

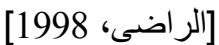

4-3-4. تقنيات عمليات الحماية للأسطح:

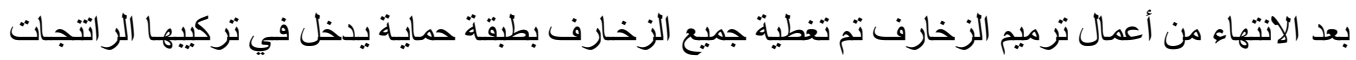
وقد نم استخدام أسلوب الرش علي الأسطح، شكل (10). [الر اضى، 1998] 
شكل (10): تثبيت الألـوان بعمـل طبقة حماية بعد الانتهاء من الترميم. [التقارير،

[2004

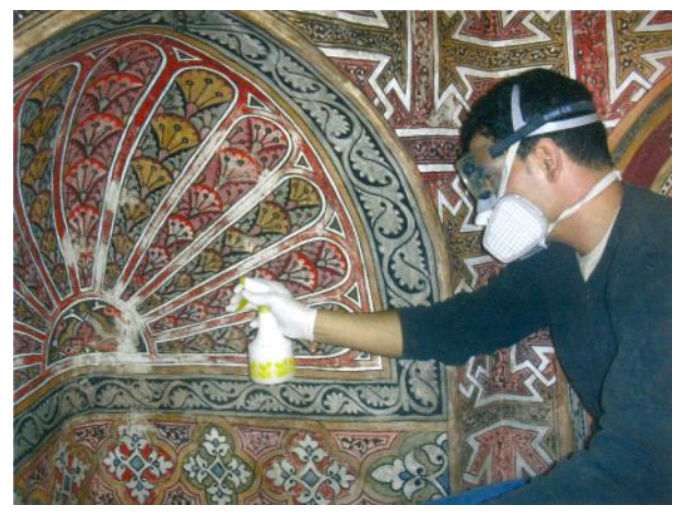

\section{5. تقييم عملية ترميم زخارف العامرية من منظور تقنيات الترميم:}

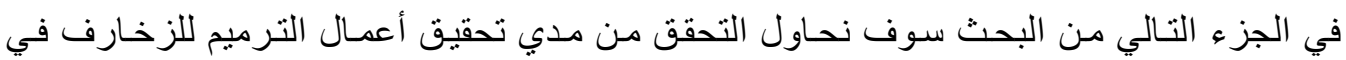
مدرسة العامرية لتقنيات الترميم الحالية.

\section{1-5. تقنيات عملية التظيف للأوساخ والأتربة:}

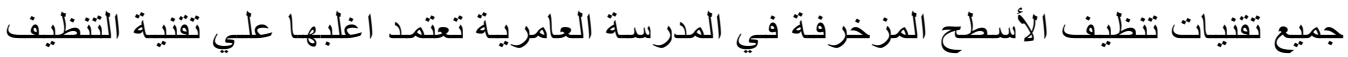

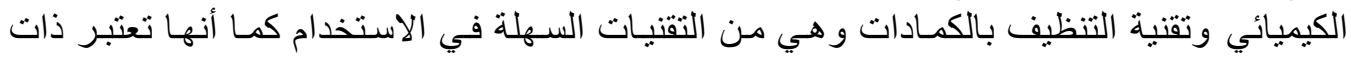

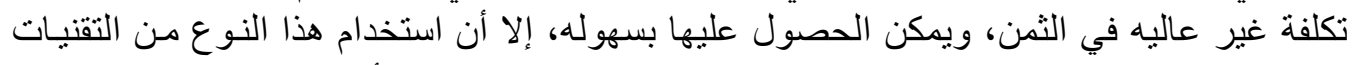

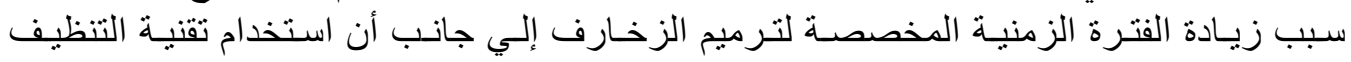

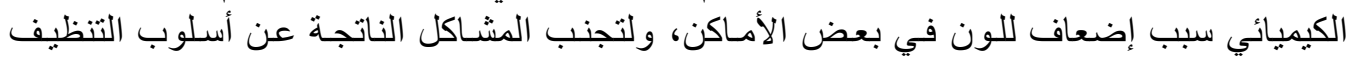

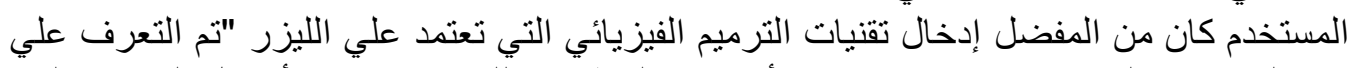

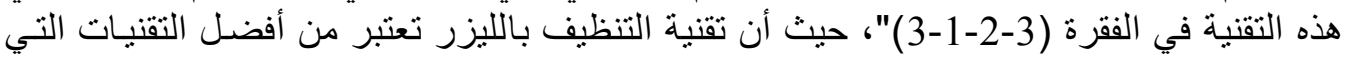

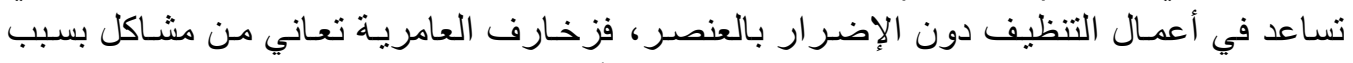

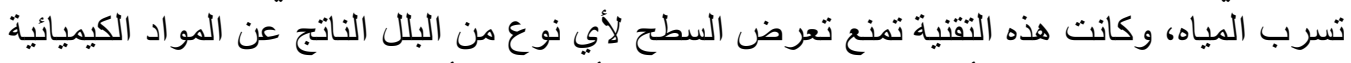

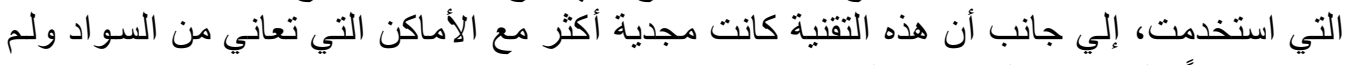
تنظف تماماً بالمنظفات الكيميائية التي استخدمت التهات

\section{2-5. تقنية معالجة الثقوق واستكمال المفقود من الزخارف:}

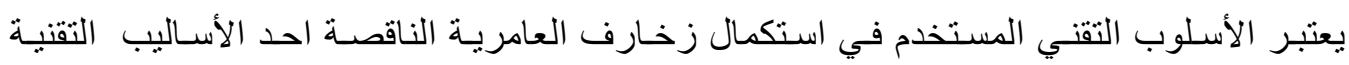

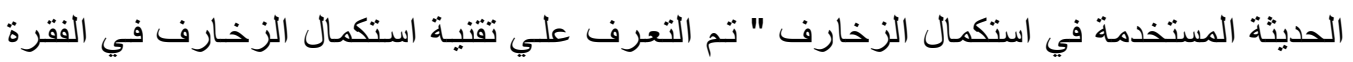

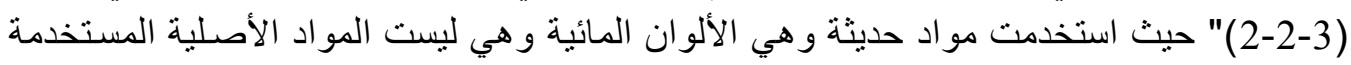

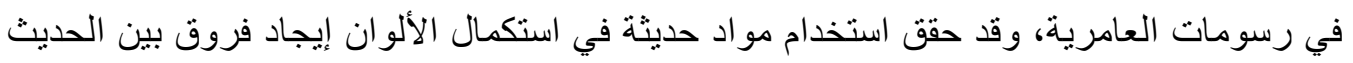

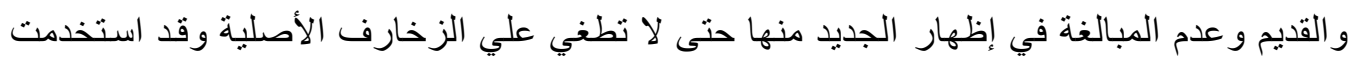

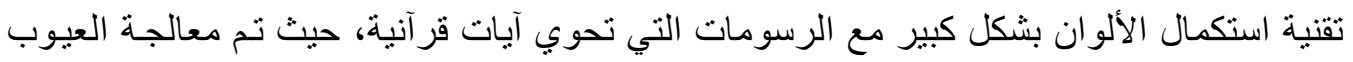

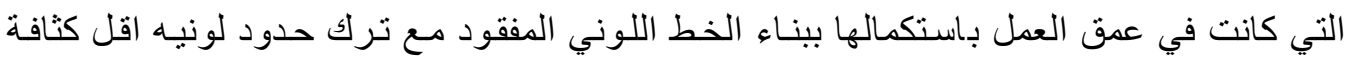

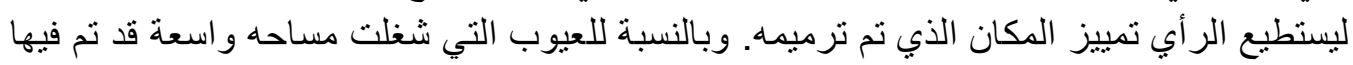

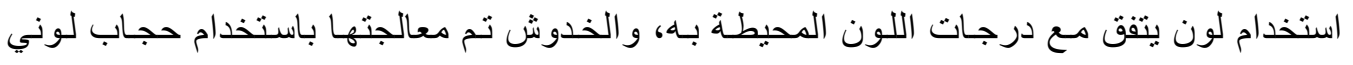

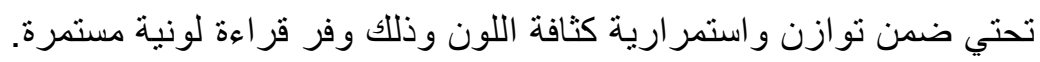




\section{3-5. تقنيات التقوية:}

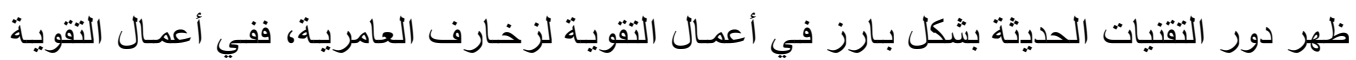

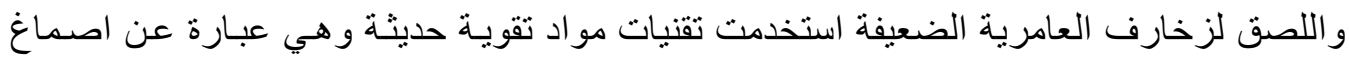

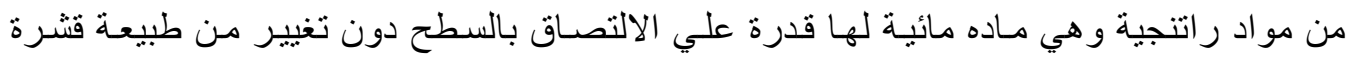

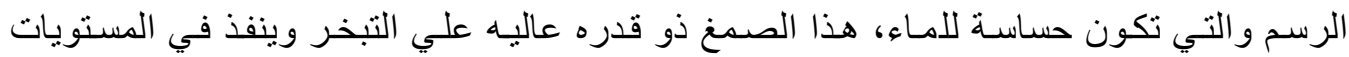

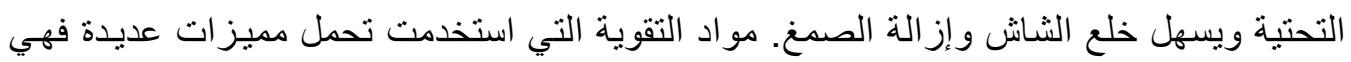

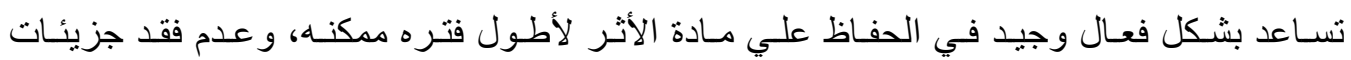

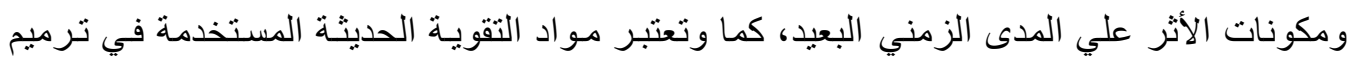

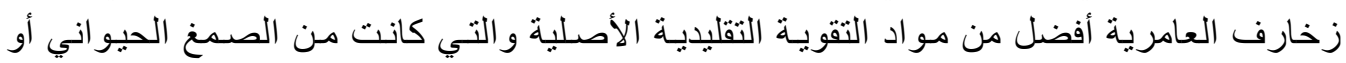
البيض و التي لا تمتلك الليونة و الاستمر ارية ومقاومة عوامل التل التلف الكيميائي و الفيزيائي كما أنها

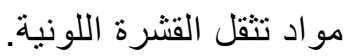

\section{4-5. تقنيات عمليات الحماية للأسطح:}

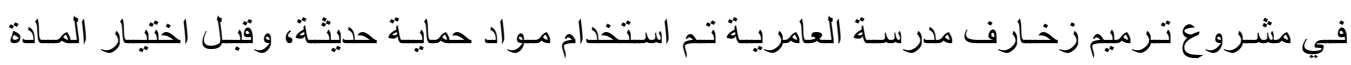

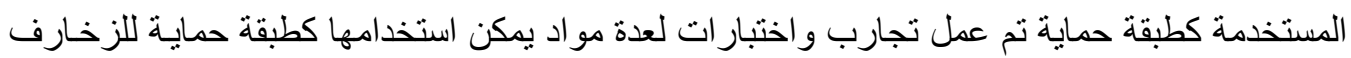

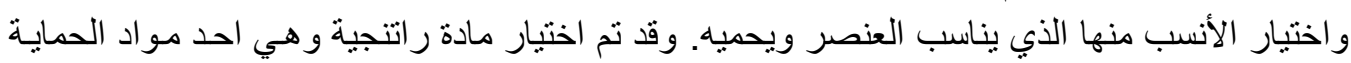

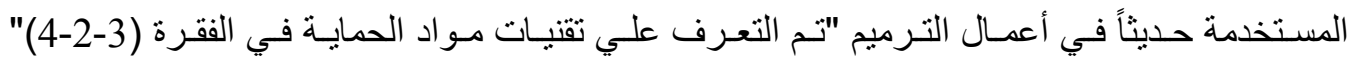

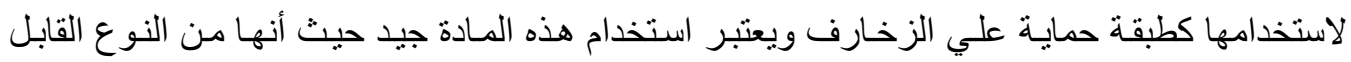

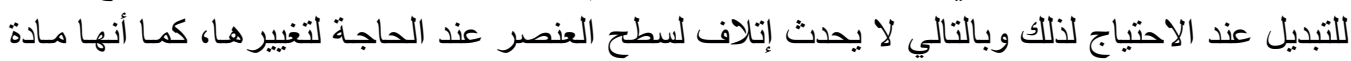

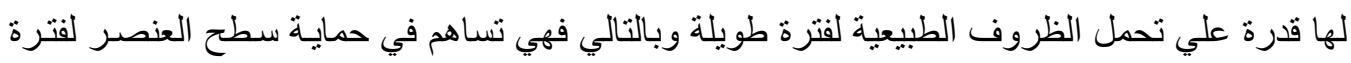

زمنية بعيدة.

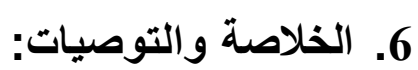 \\ 1-6. - 1 الخلاصة:}

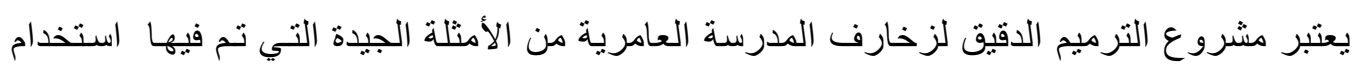

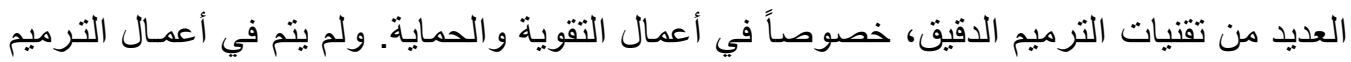

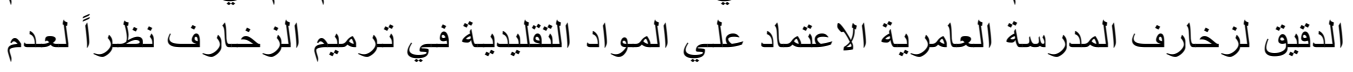

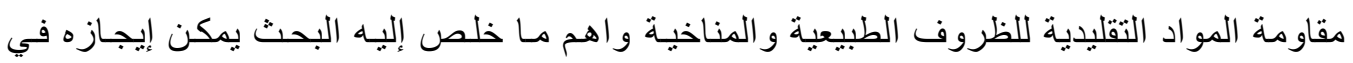
النقاط التالية: - م النية

تصاعد تقنيات الترميم الدقيق في إرجاع الصورة والهيئة الجمالية للعنصر الزخرفي من خلال تنظيفه

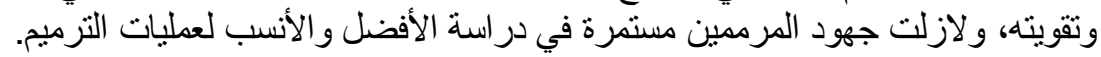

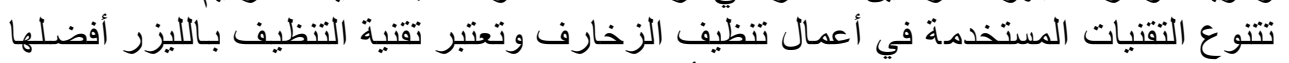

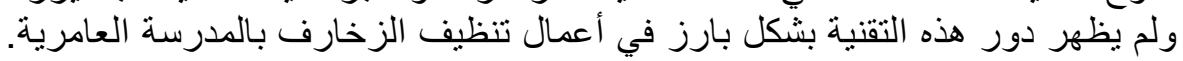

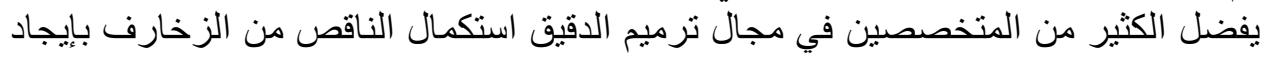

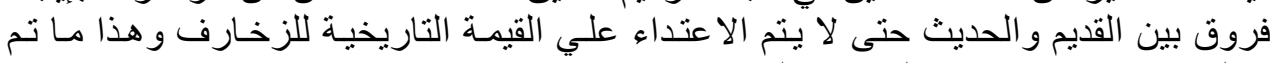

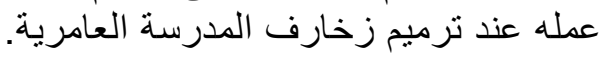

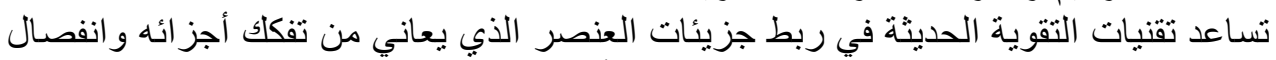

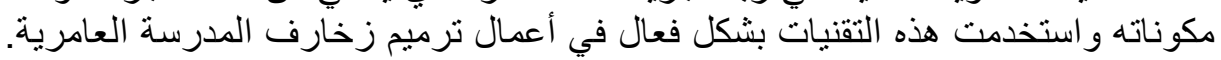


من الملاحظ أن اغلب أفر اد الكادر الذي قام بترميم زخـارف المدرسـة العامريـة كان أجنبياً وذللك لعدم وجود كادر محلي ذو خبرة بعمليات الترميم في هذا المجام فئردال.

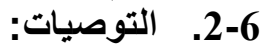

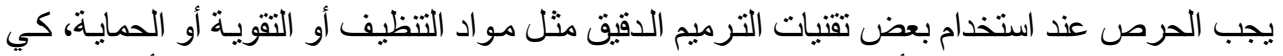
لا تسبب تفتت سطح العنصر أو بهنان في اللون، فيتم طمس المعلم التراثي و إققاده هويته الأصلية.

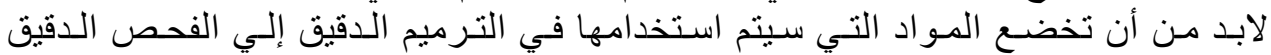

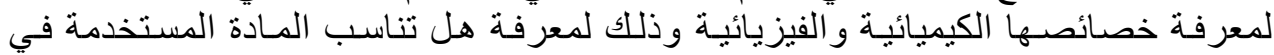

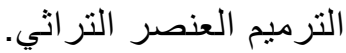

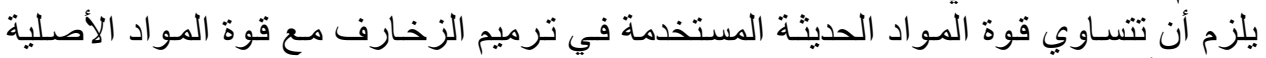

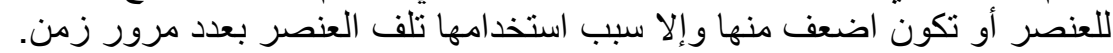

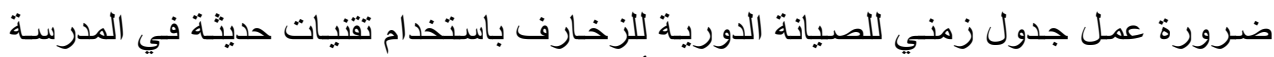

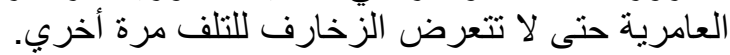

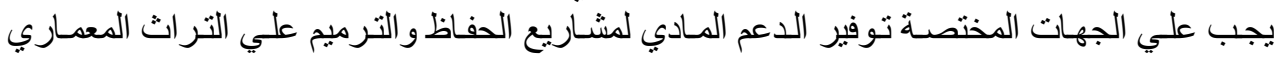

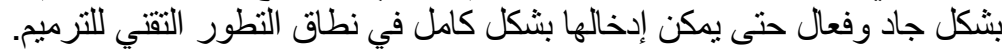

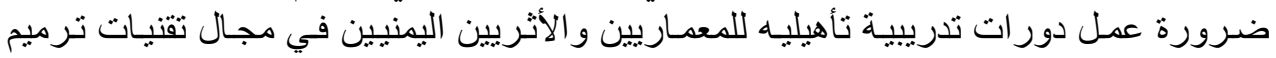
الزخارف حتى يكون هناك اعتماد علي العنصر المحلي في عملي عليات الترمين.

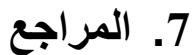

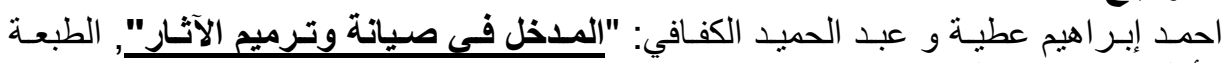

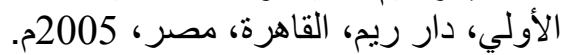

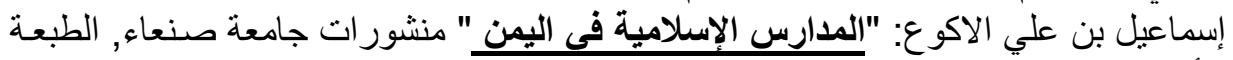

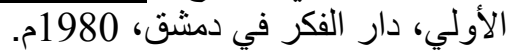

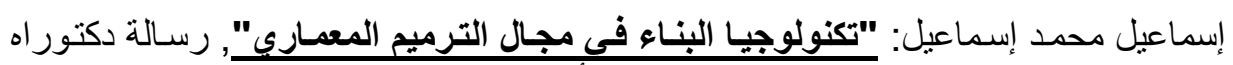

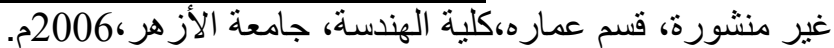

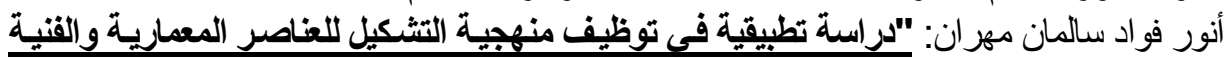

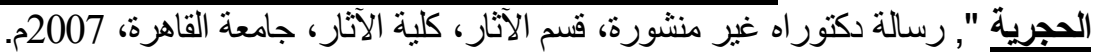

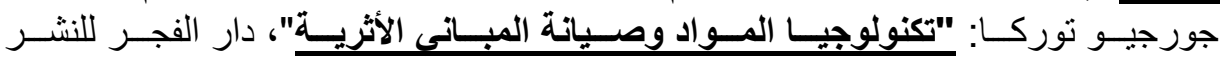

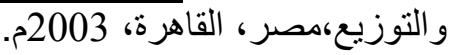
سلمى الر اضي وآخرون: "المدارسة العامرية الحفاظ على رسيوم الجدارياتي"، مركز الحفاظ

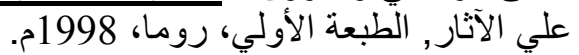

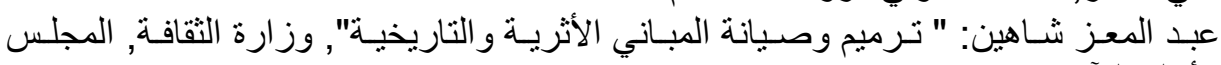

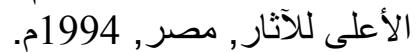
محمد عبد الهادي محمد: "مبـادئ صيانة وترميم الآثار غير العضوية "، مكتبـة زهر اء الشرق،

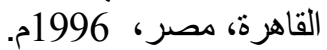

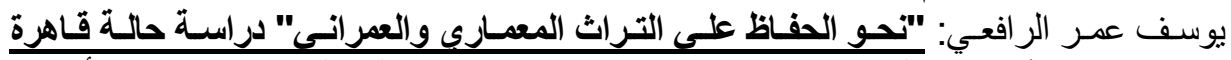

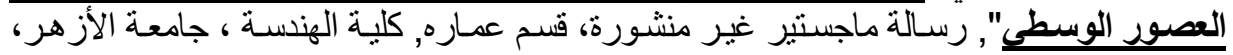
1998م.

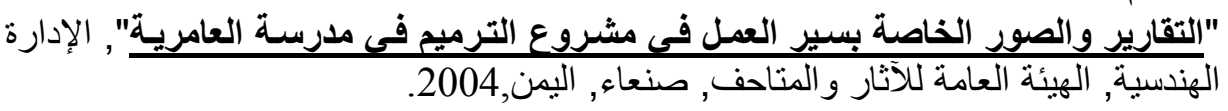

- John Ashurst, Francis G Dimes:"Conservation of Building and Decorative Stone", Butterworth-Heinemann is an imprint of Elsevier, Oxford OX2 8DP, UK,2006 
- http://archnet.org/library/parties/one-party.jsp?party_id=427

- http://archnet.org/library/images/oneimage.jsp?location_id=6287\&image_id. 